\title{
How long do satellites need to overlap? Evaluation of climate data stability from overlapping satellite records
}

\author{
Elizabeth C. Weatherhead ${ }^{1}$, Jerald Harder ${ }^{2}$, Eduardo A. Araujo-Pradere ${ }^{3}$, Greg Bodeker $^{4}$, Jason M. English ${ }^{5,6}$, \\ Lawrence E. Flynn ${ }^{7}$, Stacey M. Frith ${ }^{8}$, Jeffrey K. Lazo ${ }^{9}$, Peter Pilewskie ${ }^{2}$, Mark Weber ${ }^{10}$, and Thomas N. Woods ${ }^{2}$ \\ ${ }^{1}$ University of Colorado, Boulder, Colorado, USA \\ ${ }^{2}$ Laboratory for Atmosphere and Space Physics, University of Colorado, Boulder, Colorado, USA \\ ${ }^{3}$ School of Science, Miami Dade College, Miami, Florida, USA \\ ${ }^{4}$ Bodeker Scientific, Alexandra, New Zealand \\ ${ }^{5}$ Cooperative Institute for Research in Environmental Sciences, University of Colorado, Boulder, Colorado, USA \\ ${ }^{6}$ NOAA Earth System Research Laboratory, Global Systems Division, 325 Broadway, Boulder, Colorado 80305, USA \\ ${ }^{7}$ NOAA, NESDIS, College Park, Maryland, USA \\ ${ }^{8}$ Science Systems and Applications, Inc., Lanham, Maryland USA \\ ${ }^{9}$ Consulting LLC, Gunnison, CO, USA \\ ${ }^{10}$ University of Bremen FB1, Bremen, Germany
}

Correspondence: Elizabeth C. Weatherhead (betsy.weatherhead@ colorado.edu)

Received: 22 December 2016 - Discussion started: 20 January 2017

Revised: 30 June 2017 - Accepted: 19 July 2017 - Published: 20 December 2017

\begin{abstract}
Sensors on satellites provide unprecedented understanding of the Earth's climate system by measuring incoming solar radiation, as well as both passive and active observations of the entire Earth with outstanding spatial and temporal coverage. A common challenge with satellite observations is to quantify their ability to provide well-calibrated, long-term, stable records of the parameters they measure. Ground-based intercomparisons offer some insight, while reference observations and internal calibrations give further assistance for understanding long-term stability. A valuable tool for evaluating and developing long-term records from satellites is the examination of data from overlapping satellite missions. This paper addresses how the length of overlap affects the ability to identify an offset or a drift in the overlap of data between two sensors. Ozone and temperature data sets are used as examples showing that overlap data can differ by latitude and can change over time. New results are presented for the general case of sensor overlap by using Solar Radiation and Climate Experiment (SORCE) Spectral Irradiance Monitor (SIM) and Solar Stellar Irradiance Comparison Experiment (SOLSTICE) solar irradiance data as an example. To achieve a $1 \%$ uncertainty in estimating the offset for these two instruments' measurement of the Mg II core
\end{abstract}

$(280 \mathrm{~nm})$ requires approximately 5 months of overlap. For relative drift to be identified within $0.1 \% \mathrm{yr}^{-1}$ uncertainty $\left(0.00008 \mathrm{~W} \mathrm{~m}^{-2} \mathrm{~nm}^{-1} \mathrm{yr}^{-1}\right)$, the overlap for these two satellites would need to be 2.5 years. Additional overlap of satellite measurements is needed if, as is the case for solar monitoring, unexpected jumps occur adding uncertainty to both offsets and drifts; the additional length of time needed to account for a single jump in the overlap data may be as large as $50 \%$ of the original overlap period in order to achieve the same desired confidence in the stability of the merged data set. Results presented here are directly applicable to satellite Earth observations. Approaches for Earth observations offer additional challenges due to the complexity of the observations, but Earth observations may also benefit from ancillary observations taken from ground-based and in situ sources. Difficult choices need to be made when monitoring approaches are considered; we outline some attempts at optimizing networks based on economic principles. The careful evaluation of monitoring overlap is important to the appropriate application of observational resources and to the usefulness of current and future observations. 


\section{Introduction}

Stable, long-term time series of environmental data are critical to the ongoing investigation and understanding of the environment. One of the fundamental requirements for construction of long-duration climate records is the ability to analytically assess the characteristics of time series of different sensors so they can be combined into a single reliable record. This need is particularly valuable for satelliteborne sensors that are susceptible to a wide variety of sensitivity degradation mechanisms influenced by the space environment as well as by spacecraft, instrument and operational considerations. Many of these influences can contribute in unexpected ways to the overall instrument stability, thereby adding non-geophysical trending or structure to the combined data records compiled from multiple missions. These problems can also be exacerbated when comparing instruments with different time histories, for instance the comparison of two sensors - one during its early-orbit phase with one that has been in space for an extended length of time. For overlapping spaced-based observations, even with reliable onboard calibration and degradation correction schemes, time-limited intercomparison campaigns are important to objectively identify potential systematic errors in one or both instruments. A variety of techniques exist for merging data sets from different sources - including two different satellites - using statistical models, physical models and efforts at in situ calibration (e.g., Chander et al., 2013b; Peterson et al., 1998). Each technique has great strengths and can offer not just adjustments for merging of data sets but also estimates of uncertainty in long-term stability. Weber et al. (2016) addressed the issue of requirements on stability for detecting a desired long-term trend from a multipleinstrument time series by accounting for variations in instrumental lifetime and merging biases in a Monte Carlo simulation. Another approach to addressing satellite uncertainty, based on maintaining traceability through onboard calibration capabilities using absolute references, has been advocated through the CLARREO (Climate Absolute Radiance and Refractivity Observatory) and TRUTHS (Traceable Radiometry Underpinning Terrestrial and Helio Studies) programs (Wielicki et al., 2013; Fox et al., 2013). For both programs, verification of merging of these new approaches will be important for validation of expected agreement. For both current and proposed satellite systems, the instrument scientists will decide how to use all available information to make corrections or assign uncertainty estimates to the data should an offset or drift be detected in overlapping satellite records. Without sufficient overlap there is a limit to the magnitude of offset or drift that can be detected. This paper presents techniques that can address the stability of merged data records using observations from overlapping satellite instruments.

Measuring the small changes associated with long-term global climate change from space is both extremely important and particularly challenging. For example, the satel- lite instruments must be capable of observing atmospheric and surface temperature trends as small as $0.1^{\circ} \mathrm{C}$ decade $^{-1}$, ozone changes as little as $1 \%$ decade $^{-1}$ and variations in the Sun's output as tiny as $0.1 \% \mathrm{decade}^{-1}$ (Ohring et al., 2005). A particular challenge in the design of climate observing systems is how to preserve data quality and facilitate appropriate evaluations of observations that extend over a series of missions measuring the same geophysical quantity. A number of in-depth techniques are used by instrument scientists to understand the fundamental (Level 1) observations, including wavelength scale corrections, detector responsivity evaluation and field-of-view sensitivity monitoring. With the regular insertion of new technology driven by interest in reducing costs and/or improving performance also comes the need to separate the effects of changes in the Earth system from effects ascribable to changes and gaps in the observing system. Credible, ongoing programs of sensor calibration and validation, sensor characterization, data continuity and strategies for ensuring overlap across successive sensors are thus essential (NRC, 2000a). Multiple efforts describing key challenges and/or requirements have been published (Chander et al., 2013a; Fröhlich, 2009; Willson and Hudson, 1991; Willson and Mordvinov, 2003). Adams et al. (2014) revealed up to a $6 \%$ relative drift per decade between different ozone observing satellites, confounding some attempts to detect signs of ozone recovery. Rahpoe et al. (2015), Hubert et al. (2016) and Tegtmeier et al. (2013) all show that both drifts and biases in current satellite observing systems are often large compared to the signals of interest. The approaches presented in this paper focus on developing useful checks on the final data products (Level 2) from multiple instruments.

In the last 2 decades, there has been an increasing understanding that the merging of records, and the uncertainty associated with that merging, cannot be considered independently of the final use of the data. NRC (2000a) highlighted the need for precise inter-satellite calibration, recommending that there should be a 1-year overlap between successive Ozone Monitoring Profiler Suite missions to allow sensor intercomparison and guarantee long-term traceability. Analogously, a 1-year overlap in observations of both solar irradiance and spectral solar irradiance is part of the summary recommendations of Ohring et al. (2005). NRC (2000b) concluded that a special effort is required to preserve the quality of data acquired with different satellite systems and sensors, so that valid comparisons can be made over an entire set of observations. Randel and Thompson (2011) explored the utility of combining the Stratospheric Aerosol and Gas Experiment (SAGE) II ozone observations with tropical measurements from the SHADOZ ozonesonde network, to study interannual variability and trends. However, not all satellite records have the benefit of such a long-term in situ data set for intercomparison. Bourassa et al. (2014) quantified interannual variability and decadal trends by combining stratospheric ozone profile measurements from different satellite systems including using the SAGE II satellite instrument 
(1984-2005) with measurements from the Optical Spectrograph and InfraRed Imager System (OSIRIS) instrument on the Odin satellite (2001-present), noting significant differences between the different observational sets. These studies indicate that a more robust understanding of our data records is essential to meeting requirements and making appropriate use of the final data.

Multiple efforts are ongoing internationally to assure that emerging ground-based, in situ and satellite records can be useful to climate analyses, most notably the Global Spacebased Inter-Calibration System (GSICS) which is a joint effort by the WMO and the Coordination Group for Meteorological Satellites (CGMS) to monitor and harmonize data quality from operational weather and environmental satellites. Harmonized data sets often require adjusting for offsets, spurious drifts and instrument- or location-specific problems (Salby and Callaghan, 1997; Araujo-Pradere et al., 2011; Dudok de Wit, 2011). To improve the precision and usefulness of multi-instrument time series for identifying biases, it is necessary to remove offsets between data sources, including those resulting from (a) calibration differences, (b) spatial and temporal sampling or resolution differences, (c) changes in data processing versions, (d) inherently different spectral sensitivities, (e) different instrument types with varying inherent vertical coordinates, and (f) changes in instrument orientation or orbital characteristics or collection times; as examples see Chander et al. (2013b) and Toohey et al. (2013). These potential problems are further exacerbated by temporal gaps or insufficient overlap in the satellite records.

In this paper, we estimate the direct impact of length of overlap between satellites to the continuity of data from two overlapping satellites. We examine three separate factors that are of direct importance to the users and creators of merged satellite data sets: the quantified offset of the two data sets, the drift between the two data sets and the impact of sudden jumps in the data during periods of overlap. We note that intercomparison of satellite records cannot, in isolation, determine which of two systems is more accurate or stable. Indeed, agreement of two observing systems can occur when both are similarly inaccurate or similarly drifting, and instruments can drift outside of the intercomparison periods. However, intercomparisons offer valuable, independent assessment useful for developing a long-term record. For illustrative purposes, we look at ozone, temperature and solar radiation satellite records and discuss how these three factors can affect the long-term records of these parameters. We present techniques for evaluating overlapping data with the solar data set because the data are less dependent on satellite drift, diurnal matchups and differences in the instrumentdependent field of view. We note that the usefulness of overlapping data is highly dependent on the length of overlap and the ability to match overlapping data with high precision. In the final section of this paper, we outline methods for optimizing the set of choices which are needed to create a longterm and stable climate record under a variety of constraints, most notably economic constraints. Optimization will result in better use of resources to achieve more accurate and stable merged data sets.

\subsection{Overlap of Earth observation satellites}

The value of satellite observations to understanding the variations, climatologies and changes in the Earth's atmosphere has been profound. Temperature, ozone, water vapor, aerosols and carbon are now understood in ways unimaginable compared to the pre-satellite era. Continued development of new technologies - including sensor development, calibration capabilities and refinement of occultation techniques - has resulted in continued improvements in our observing systems. However, the challenge remains to merge the observations from these evolving systems into scientifically and societally useful observations.

\subsubsection{Ozone}

Some of the most studied satellite records are the internationally sponsored ozone records (WMO, 2014, and reference within; Staehelin et al., 2003). Since 1978, there have been near-continuous space-based observations of ozone profiles from a combination of missions. Temporal overlaps between these instruments have allowed detailed intercomparisons to play a key role in assessing the precision, accuracy, and long-term drift of the instruments (WMO, 1989, 2011a, b; Bodeker et al., 2001). However, these overlaps have been somewhat serendipitous; little commitment has been made to ensure the continuity and long-term traceability of the full ground-based, in situ and satellite ozone measurements. The satellite ozone records, as with the temperature records, benefit from multiple observations - both satellite and in situ over the past 4 decades (Eckert et al., 2014; Staehelin et al., 2003), resulting in insights into the delivered accuracy and stability of satellite measurements.

Figure 1 shows the result of merging the Global Ozone Monitoring Experiment (GOME), Scanning Imaging Absorption Spectrometer for Atmospheric Chartography (SCIAMACHY) and GOME-2A total ozone time series (Weber et al., 2011, 2017) into a continuous time series. In this case, the SCIAMACHY and GOME-2A observations (thin blue and green lines) were successively bias-adjusted to be continuous with the original GOME data. Biases (offsets) were determined as a function of latitude in steps of $1^{\circ}$ using monthly zonal means. Despite extensive pre-calibration efforts and monitoring of instrument performance, differences are noted between data from the overlapping satellites. There appears a drop of the original GOME-2 data record during the 2009-2011 period relative to SCIAMACHY, which seems to be larger than the overall bias between two data sets. In this case the very large overlap period from 2007 until 2012 was an advantage, and no further corrections beyond the latitude dependent biases were needed to adjust 


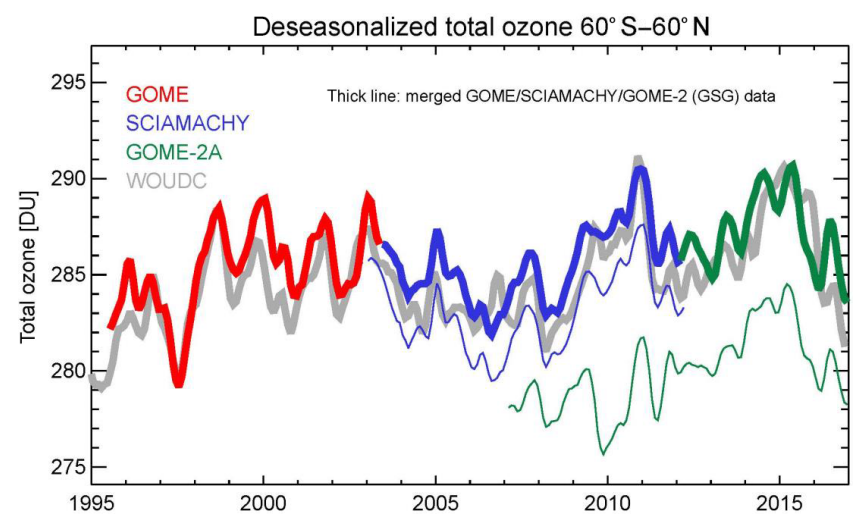

Figure 1. The thick and multi-colored line is the merged total ozone satellite record (GSG data) from GOME, SCIAMACHY and GOME-2A (Weber et al., 2011, 2016a). The thin blue and green lines indicate the original data before offsets were corrected to create a continuous record. The success of the analytical effort to combine these three satellite records is confirmed by the good agreement of the merged data set with the zonal mean data derived from ground-based Brewer and Dobson data as part of the WOUDC (World Ozone and UV Data Center, update from Fioletov et al., 2002), which is presented as the thick grey line.

GOME-2. Due to this non-physical drop in the GOME-2A data, the SCIAMACHY data became the preferred choice in the merged (GSG) data set during the overlap period (20072011). In contrast the overlap period for SCIAMACHY and GOME was less than 10 months (2002-2003). Additional corrections beyond a simple bias are difficult and may require the use of external reference data, although the need for additional corrections may be indicated from satellite overlap data. The long-term stability of these data is critical for estimating ozone recovery and understanding the complex long-term factors affecting stratospheric ozone. Lessons from these overlap data serve to offer guidance for future decisions on satellite observations and overlap periods.

\subsubsection{Temperature}

Perhaps no other set of satellite records has been as studied as the temperature records derived from the Microwave Sounding Unit (MSU) and Advanced Microwave Sounding Unit (AMSU) satellites. Two distinct challenges complicating the algorithms needed to develop reliable long-term temperature records are that (1) multiple satellites, in situ and ground-based measurements are available each with unique characteristics, and (2) the level of agreement differs with latitude and altitude. Multiple sources of data can complicate merged data sets because different choices, even when reasonable, can lead to different long-term characteristics in the record (e.g., Thorne et al., 2005; also see Sect. 3 of this paper). However, multiple records also allow different groups to produce independent merged data sets which have long overlaps and can be directly compared. Through these com- parisons we gain valuable information about the uncertainties that arise from the merging process itself and whether the data sets are stable relative to the requirements of the analysis.

Figure 2 shows the residuals from two independently merged data sets; the results show notable month-to-month differences between a merged data set of MSU Channel 4 and AMSU Channel 9 monthly averaged deseasonalized data compared to a combined data set from six satellite instruments providing high-vertical-resolution temperature data: MIPAS, ACE-FTS, SMR, GRACE, CHAMP and TSX. Both channels are designed to observe the lower stratosphere. A full description of this merged temperature record and comparisons with the MSU-AMSU merged record are given in Penckwitt et al. (2015). The comparisons of overlapping data, after offset and drift have been removed, show several relevant features. First, the variability in the overlapping data varies significantly by latitude. Second, differences in the merged data sets can be remarkably large - over $0.5^{\circ} \mathrm{C}$ for latitudinal averages - despite differences between data sets being minimized in the merging process and offset and drift between the compared data set being removed. Third, even when the linear drift over the length of the overlap is removed, the data show apparent drifts that last for several years in each latitude band. Such variations can limit the usefulness of the merged records but can also highlight issues with particular data sources that can then be addressed. The latitudinal dependence of the variability may indicate regions that are better suited for analysis than others, though in all cases the physical reasons for the correlated variability and potential drifts need to be carefully examined. The stability levels of satellite temperature data sets are critical for understanding the merged and complex feedbacks that determine regional long-term temperature changes; understanding apparent offsets and drifts between different sources of information is important, particularly when they are large compared to expected trends.

\subsection{Planning for needed homogeneity}

Detecting and understanding long-term changes require some of the most challenging stability criteria in order for confidence to be placed on the final results. A number of individuals and coordinated groups have worked to define the requirements for Earth observations, including the recently completed effort by WMO (2011b), which addresses the stability needed for various parameters. In the absence of explicit requirements for limits on drift, we suggest that the standard error of the drift, at the $1 \sigma$ level, be limited to half of the trend that one is seeking to detect. For example, if a monitoring system is designed to detect a trend of $0.2^{\circ}$ decade $^{-1}$, the unchecked drift of the system should be less than $0.1^{\circ} \mathrm{decade}^{-1}$ at the $1 \sigma$ level. While for Earth sciences, the projected trend is dependent on the climate model and assumptions used to estimate future trends - as well as 

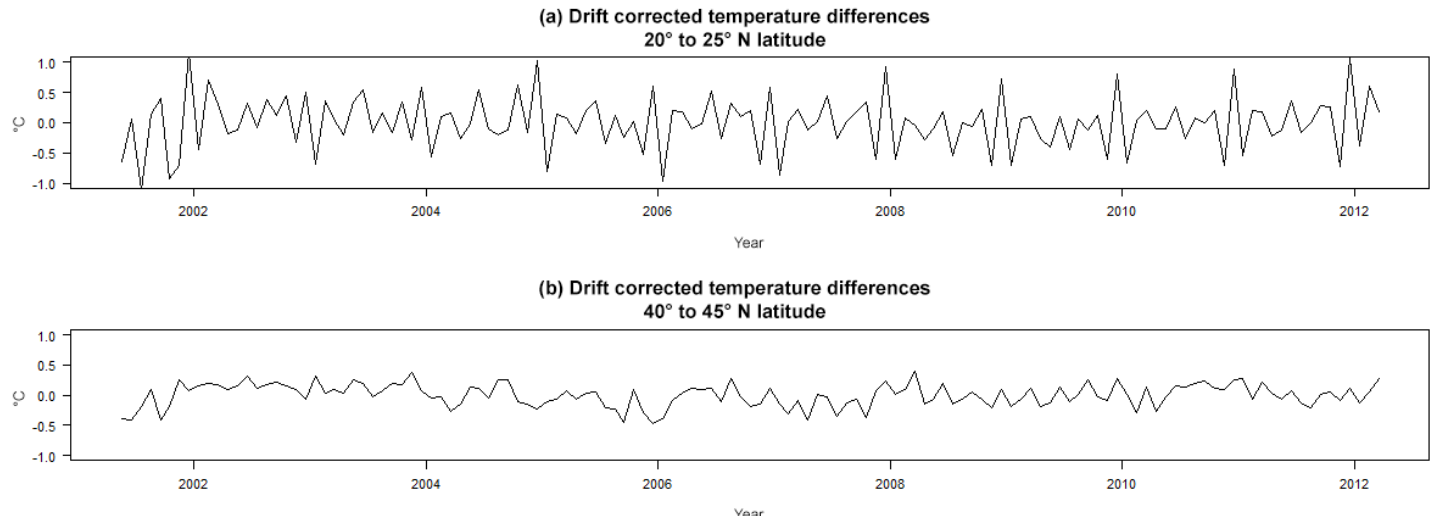

(c) Drift corrected temperature differences $60^{\circ}$ to $65^{\circ} \mathrm{N}$ latitude

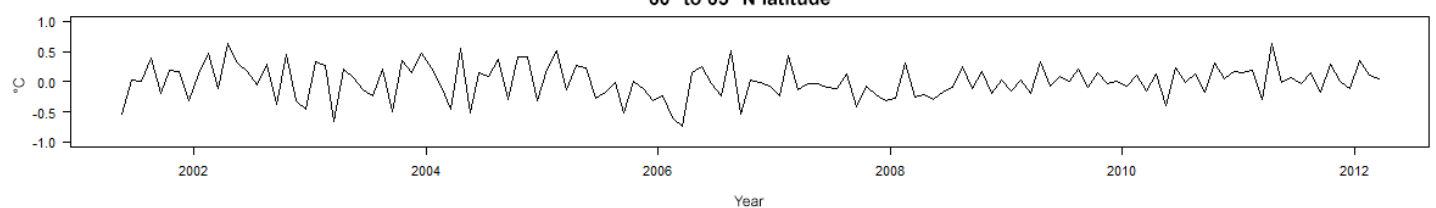

Figure 2. Monthly differences between a merged MSU Channel 4-AMSU Channel 9 satellite temperature record and a second merged temperature record based on two satellite-based mid-infrared spectrometers (ACE-FTS and MIPAS), a microwave sounder (SMR) and three satellite-based radio occultation experiments (GRACE, CHAMP and TSX) (Penckwitt et al., 2015). Shown are the differences once mean offsets and long-term drifts for each latitude band are removed through a statistical regression (in ${ }^{\circ} \mathrm{C}$ ). The top plot is for $20-25^{\circ} \mathrm{N}$; the middle plot is for $40-45^{\circ} \mathrm{N}$ and the bottom plot is for $60-65^{\circ} \mathrm{N}$. These plots show the variability in overlap is highly dependent on latitude, as is often the case with Earth observations.

the location and time of projected trends - this estimate can be used as a starting point for discussions on how well the drift should be confined. When the verification of drift cannot be held to the level of projected trends, there can be serious questions as to the usefulness of the monitoring system for trend identification.

The user communities, including the climate community, continue to request high stability from satellite observations (WMO, 2011a; Wulfmeyer et al., 2015; Ohring et al., 2005). A variety of ideas have been offered to allow for more accurate satellite observations: onboard calibration, independent verification and in-depth modeling of instrument performance can all assist in characterizing the accuracy, biases and stability of the satellite measurements, many based on the fundamental measurement equations and availability of internal instrument monitoring. There is a long and valuable history of efforts to attempt in-flight calibration, particularly on multi-spectral sensors (Slater et al., 1996). GSICS coordinates the development of tools to intercompare different Earth observing systems (Hewison et al., 2013; Wu et al., 2009). Through careful analysis of spectral signals, relative stability can be assessed, and even small problems with individual sensors can be identified. Ground-based and in situ observations continue to offer some of the most useful information for constraining offsets and drifts in satellite instrument as well as providing reliable, direct information on the Earth system. Both campaigns and long-term monitor- ing efforts continue to help verify the accuracy and stability of satellite observations. Despite current efforts, long-term stability and absolute calibration still present a challenge to current internal-consistency methods, leading many to look to other approaches for absolute calibration, traceability and the ability to verify stability.

Perhaps the most innovative and needed advancements will come though future in-flight calibration approaches. The development and use of these high-accuracy climate benchmark instruments has been advocated for since the early 2000s and described in the NISTIR 7047 (2004) and ASIC3 (2007) workshop reports. These high-accuracy instrument systems will provide two fundamental products of great value to the climate science community: (1) reliable long-term records of basic climate forcings, response and feedback for analysis and climate model verification, and (2) in-flight calibration standards for environmental operational satellite sensors including weather satellites that do not have a rigorous pre-flight radiometric calibration requirement or the ability to perform degradation corrections on orbit. These ideas have been formulated in the visions of CLARREO and TRUTHS but may be tested in other reconfigurations (Wielicki et al., 2013; Best et al., 2008; Fox et al., 2013; Tobin et al., 2016). Until such techniques are developed and tested, ground-based and in situ observations continue to offer some of our best ways of tying satellite observations to traceable standards. Efforts are already underway 
to estimate uncertainties due to the matching of independent satellites with these reference sources (Feldman et al., 2011; Lukashin et al., 2013).

Even with future improvements in satellite observation accuracy, the challenge will remain to understand and merge records from different satellites - each potentially using its own calibration and collection approaches - to provide a single observational record. One of the key factors that we can control is the length of overlap between existing and future satellites. Analysis of an overlap record can only give us an estimate of relative drift, but in the absence of traceable inflight calibration, it is often one of our best checks on longterm stability of the final data products. Understanding that decisions on overlap will directly affect both the cost of monitoring and the value of the final data set for evaluating longterm changes in climate, we propose approaches to objectively evaluate the length of overlap needed to achieve a specific stability in the merged data record. In Sect. 8 we offer an approach to evaluate how important overlap is compared to other choices that can help improve a long-term data record.

\section{Approach}

The statistical analysis techniques developed by Weatherhead and collaborators (see, for example, Weatherhead et al., 1998, 2000) provide a basis for addressing the length of time needed for adequate overlap based on the magnitude of the signal variance as well as residual noise autocorrelation. In this paper, we perform a case study by applying these techniques to existing SORCE SIM and SOLSTICE instrument data, thereby illustrating the use of statistical methodology to estimate the length of overlap needed to achieve records of specified stability. The techniques discussed herein may be useful not only for instrument scientists pursuing improvements in onboard instrument corrections but also for mission planning by program managers to ensure the best overlap characteristics of adjoining missions; the basic concepts of uncertainty from merging of data sets are directly useful to those interested in using the data.

In order to appropriately analyze satellite observations, it is necessary to understand and appropriately incorporate the available information on the pre-flight calibration of instruments and in-flight expected behavior. The detailed inflight circumstances that produce instrument instabilities are highly specific to individual sensors, so the best practice is to employ instrument telemetry and on-orbit calibration methods traceable to international standards. Such approaches can be used to develop detailed measurement equations that can account for the occurrence of degradation and correct the measured signal to produce high-quality Level 1 data. The measurement equation carries its own uncertainties and, in principle, allows for the estimation of time-dependent uncertainties as a function of mission day. This measurement equation approach is advocated in the "Guide to the expres- sion of uncertainty in measurements" (JCGM, 2008) by the Joint Committee for the Guides in Metrology (JCGM) and relies only on the known and measurable properties of the subsystems that compose the full instrument used for the observation. Instrument teams apply these corrections to produce the final Level 2 data in an effort to provide the most accurate measurements independent of outside data sources. For this study, we assume all relevant corrections have been made to the data to account for known biases and drifts in the instrument.

\subsection{Introduction of SORCE SIM and SOLSTICE instruments}

For illustrative purposes, we will use two sets of data from the Solar Radiation and Climate Experiment (SORCE) satellite: concurrent data from the Solar Stellar Irradiance Comparison Experiment (SOLSTICE) and the Spectral Irradiance Monitor (SIM). SORCE was launched on 25 January 2003 and has conducted daily measurements of the spectral and total irradiance with only a few gaps in the time series, the longest gap being a 209-day period starting on 31 July 2013. This gap was caused by a reduction in charging capacity of the spacecraft batteries and has been successfully mitigated by operating the instruments in a day-only operation mode that does not rely on keeping spacecraft subsystems operational on the nighttime portion of the orbit. The instruments for the SORCE mission are described in a series of papers published in Solar Physics related to the design, operation, calibration and performance of the SORCE instruments. Harder et al. (2005a) describe the scientific requirements, design and operation modes for the instrument. Harder et al. (2005b) discuss the fundamental measurement equations and the pre-flight calibration methodology for the instrument. A third paper (Harder et al., 2010) continues the discussion of the absolute calibration of the instrument describing additional post-launch characterizations using flight spare components and comparisons with the SORCE and UARS SOLSTICE instruments and the ATLAS 3 composite (Thuillier et al., 2004). Additional in-flight comparisons with the European Space Agency (ESA) Environmental Satellite (ENVISAT) SCIAMACHY instrument are discussed in Pagaran et al. (2011). Similarly, McClintock et al. (2005a, b) describe the SOLSTICE instrument design and calibration. Snow et al. (2005) describe the important solar-stellar calibration process that forms the basis of the on-orbit degradation corrections.

\subsection{Setup for SIM-SOLSTICE comparison}

Solar irradiance is a crucial driver in the Earth's atmospheric system, influencing variability, circulation and long-term behavior of the atmosphere and having a direct role in atmospheric chemistry for the upper layers of the atmosphere. A motivation for this solar irradiance study, as is true for 
most other long-term satellite monitoring efforts, arises from the need to understand the length of time needed for the overlap of the currently operating SORCE mission with the next-generation Total and Spectral Irradiance Sensor (TSIS). TSIS is currently scheduled for launch in the fourth quarter of 2017 for deployment on the International Space Station. While Earth observations often require a minimum of a 1year overlap to cover the full range of expected observations, such arbitrary criteria ignore longer-timescale phenomena, including ENSO and NAO, and are impractical for covering a full 11-year solar cycle in a planned overlap period. Here we are applying analytical techniques to understand the length of time needed to quantify the offset between two satellite observing systems and to understand the drift between two satellite records (Weatherhead et al., 1998). While it is unclear whether the TSIS-SORCE overlap will mimic the findings from the comparison of the two SORCE instruments, this effort will examine how potential instrument anomalies and systematic errors in the degradation corrections affect the ability to determine the length of time needed to determine a drift difference in the two sensors. For this study, we are using a subset of 3 years of data from 18 November 2005 to 31 December 2008 (1140 days), characterizing the time period corresponding to the descent into the solar minimum condition of solar cycle 23 with the minimum value apparently in the January-February period of 2009. This time period was selected to approximate what would be expected from an overlap comparison campaign conducted during the descending phase of solar cycle 24 , projected to be in the 2019 time frame. However, the solar cycle 23 minimum is the longest and quietest time period of the space age (Schrijver et al., 2011; Araujo-Pradere et al., 2011, 2012), but our analysis does not rely on this situation persisting into the solar cycle minimum. This paper targets common observations of the irradiance in the $280 \mathrm{~nm}$ spectral region, which includes the highly variable core of the magnesium $(\mathrm{Mg})$ II lines. This region was selected because the variability of the Mg II lines is an important indicator of solar chromospheric variability and is frequently used for space weather applications (Viereck et al., 2004; Marchenko and DeLand, 2014) and as a proxy for solar influence on stratospheric ozone and temperature (Hood and Zhou, 1998). It should be noted that the SIM (version 22) and SOLSTICE (version 15) used in this study are used as reported on the publically available SORCE Web page (http://lasp.colorado. edu/home/sorce/data/ssi-data/). SIM and SOLSTICE corrections are made independently of one another, but the higherresolution $0.1 \mathrm{~nm}$ resolution SOLSTICE data are integrated into a fixed $1 \mathrm{~nm}$ bin centered at $280 \mathrm{~nm}$. The SIM instrument has a FWHM resolution of $1.1 \mathrm{~nm}$ with six samples per resolution element. While some offset in irradiance is expected due to spectral sampling used to generate the data products, the difference is fixed and does not drift as a function of time due to the well-defined wavelength scale and spectroscopic properties of the two instruments (Harder et al., 2010).
Figure 3 shows the time series comparison of SOLSTICE version 15 and SIM version 22 used in this study. These overlapping data sets illustrate three types of inconsistencies that occur in geophysical records and have been noted in both the ozone and temperature satellite data sets described above. These three sources of uncertainties combine and contribute to the length of overlap needed to derive a robust climate record from satellite records.

There is an offset of about $0.5 \%$ in the pre-flight calibration between the SOLSTICE and SIM. The pre-flight absolute calibration is on the order of $1-2 \%$ and thus within the ability to absolutely calibrate the spectrometer. Note that the observed differences in Fig. 3 are within the expected preflight calibration uncertainty, but these differences are still large relative to some scientific uses for solar data. The value of overlapping missions for an appropriate period of time is the ability to verify pre-flight calibration estimates of uncertainty and potentially improve the long-term data sets for scientific applications.

There is an apparent drift in the data between the two instruments. The advancement in SOLSTICE version 15 contains a new correction that removes an annual oscillation in the data induced by a change in the size of the degradation spot "burned in" to the collimator mirror - see McClintock et al. (2005a) for more detail on the optical configuration. As the Earth-satellite system moves around the elliptical orbit of the Sun, a different illumination occurs on the first optic, thereby modulating the intensity of light that propagates through the rest of the optical system. This same effect occurs in the SIM data but has been a part of the standard degradation correction for the last versions. SOLSTICE version 15 tends to flatten the apparent long-term magnitude of the $280 \mathrm{~nm}$ variability relative to earlier SOLSTICE versions.

There are jumps in the time series related to spacecraft and instrument anomalies. Significant events are identified in instrument and spacecraft housekeeping telemetry and changes in behavior before and after these events can be characterized and corrected in the time series. Examples of these phenomena are seen in Fig. 3, where SOLSTICE experienced a failure of the mechanism that changes the entrance slit from the solar to the stellar mode on 27 January 2006. The slit was moved back into position for continuous solar observations but did not return to the exact same position, so the optical path through the instrument changed and therefore disrupted the degradation corrections and the wavelength scale. Similarly, a spacecraft safehold event on 14 May 2007 caused the instruments to become very cold and significantly changed the SIM wavelength scale and perhaps the transmission properties of the instrument. The change in the SIM wavelength grid is apparent in the uncorrected data, but in Fig. 3 the data are interpolated onto a standard mission-length wavelength scale and do not appear as a jump in this figure. The 2007 safehold event had little effect on the performance of the SOLSTICE. The jump associated with the 2006 SOLSTICE slit anomaly has also been corrected, and the change 


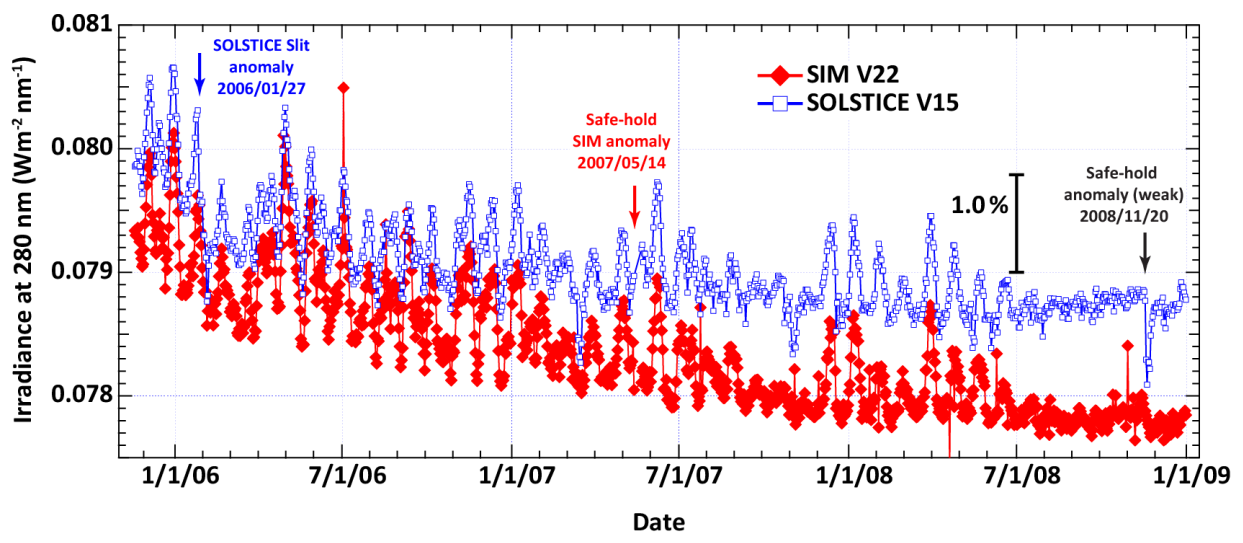

Figure 3. An 1140-day segment of concurrent SORCE SOLSTICE (version 15) and SIM (version 22) data during the descending phase of solar cycle 23. The 27-day variations seen in this plot are caused by solar rotational modulation of active regions dispersed on the Sun and are not due to instrument noise; note that this modulation is apparent in both data sets. This data segment contains all three uncertainty sources identified in this study: offsets, drifts and jumps.

in character seen in SOLSTICE data at this time represents the best compromise over the full wavelength range of the instrument.

The next sections of this paper will address the effects of these three anomalies (offsets, drifts and jumps) in the SORCE data sets and discuss their impacts on data set uncertainty. The primary contribution of this paper is to quantitatively address the impact of the length of measurement overlap on helping verify a specific level of stability in the final data set.

\section{Offsets}

Efforts at merging satellite data in the past have focused on deriving offsets to limit relative differences before combining data from different sensors into a continuous record (e.g., Wentz and Schabel, 1998; Santer et al., 2003; Smith et al., 2008; Dudok de Wit et al., 2008; Chander et al., 2013b).

One of the most studied issues underscoring the importance of proper treatment of multiple satellite records involves the corrections and merging of MSU temperature records. Christy et al. $(1995,1998,2000)$ accurately pointed out that trends from satellite temperature records were not in agreement with other temperature records and showed a cooling of the troposphere rather than a warming. Additional work showed that a number of corrections to the satellite record could make a direct and notable difference on the trend derived from the resulting data (NRC, 2000a, b; Zou and Qian, 2016). Some of the most salient lessons from this effort were summarized by Thorne et al. (2005), who concluded, among other points, that "individual adjustments will a priori retain a non-climatic signal of unknown sign and magnitude regardless of how reasonable and physically plausible the chosen homogenization approach". The uncertainty of merging satellite data records is a continual challenge with a variety of approaches employed, including comparison to ground-based records, statistical intercomparison of satellites by latitude, time of day and season, and use of physical models to look for appropriate consistencies with available data. Details of the merging process directly influence the resultant trends and add to the level of uncertainty in the final data sets (Karl et al., 1986). In this section we consider the case where overlap is non-existent, and for the case where overlap exists we consider the length of time required to achieve a specific uncertainty in an overlapping set of data. These cases illustrate the need for overlap periods of sufficient duration to make a quantifiable improvement in the long-term record.

We consider the straightforward method for merging two sequential (non-overlapping) data records by requiring the mean level of the 3 years of data prior to the discontinuity be equal to the mean level of the 3 years of data after the discontinuity. In such a situation, those 6 years of data are being forced, by the algorithm, to have very little trend. Imagine a situation where there are two such discontinuities in a 20year record; more than half of the data have been coerced to have virtually no trend, making the resultant data unreliable for many long-term monitoring uses. The case of no overlap can occur for a variety of reasons, including the sudden loss of a satellite or problems on launch of newer satellites. The end result of any offset correction will have a direct impact on the magnitude of the resulting trends.

To estimate the time needed for overlap requires an estimate of what the overlap time series would look like. We use monthly averages, a common standard in many climaterelated research efforts for several reasons: monthly averages avoid the matchup issues and potential nonlinearity of shortterm features, such as storms (Araujo-Pradere et al., 2004), and offer enough resolution to observe long-term behavior of 


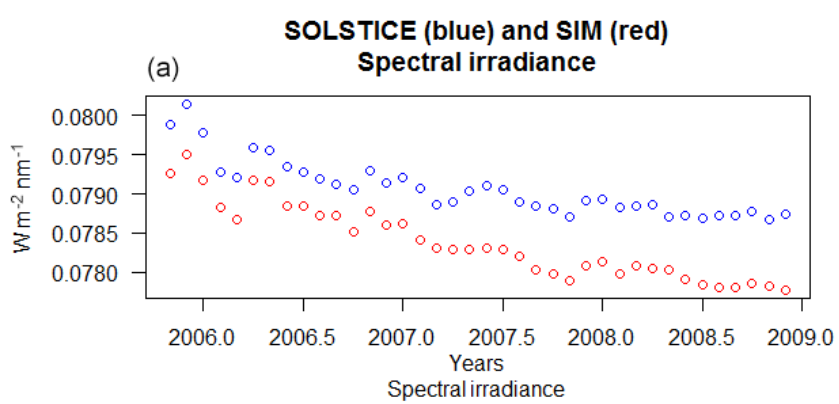

(b)

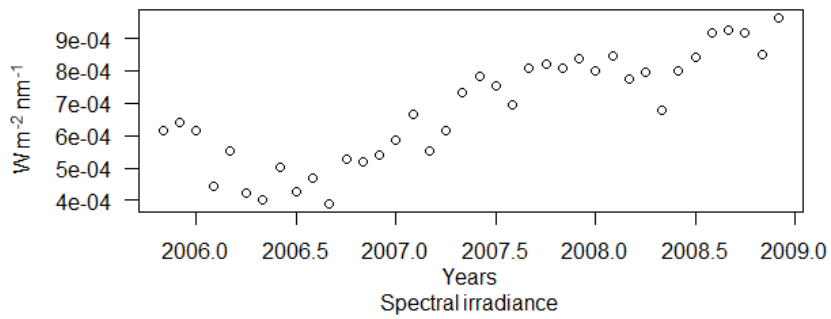

Figure 4. Monthly averaged SOLSTICE data and SIM data (a) and SOLSTICE-SIM (280 $\mathrm{nm} \mathrm{Mg} \mathrm{II)} \mathrm{data} \mathrm{(b)}\left(\mathrm{W} \mathrm{m}^{-2} \mathrm{~nm}^{-1}\right)$ as a time series for the period October 2004 through December 2008. The data show that the observed differences are small but do not appear to be stable; thus a simple level shift to bring the two data sets into agreement may not fully address the matchup and stability issues of the data set.

the matchup. ${ }^{1}$ If, as is the case of the SOLSTICE-SIM overlap, the difference between the two data sets looks like Fig. 4 with significant agreement in observed variability, the paired data can be used to estimate offsets and uncertainties in the derived offsets.

The overlap data depicted in Fig. 4 show a mean difference between the two data sets of $6.8 \times 10^{-4} \mathrm{~W} \mathrm{~m}^{-2} \mathrm{~nm}^{-1}$, with a standard error on this mean of $2.7 \times 10^{-5} \mathrm{~W} \mathrm{~m}^{-2} \mathrm{~nm}^{-1}$ when the classic standard error calculation ignores autocorrelation. However, this figure does not support the assumption that the observed differences between SOLSTICE and SIM are stable and would continue beyond the observed end of the analysis period of December 2008 because of the apparent drift in the differences. For cases when a drift is not involved, we can make use of the standard formula for the standard error on the mean of the observed time series of differences when

\footnotetext{
${ }^{1}$ While it could be argued that there is nothing unique about the time step of 1 month, it is a common practice in climate analyses. However, the example data sets used in this paper measure extraterrestrial solar radiation. With the Sun's rotation of 27.2753 days, we have a natural time frame close to a monthly average. In Appendix A we carry out the calculations in this paper with monthly averages and with averages based on the solar rotation schedule; we see no notable change in the basic conclusions when adopting the more natural solar rotation schedule instead of monthly averages.
}

simple autocorrelation is present:

$\mathrm{SE}_{\text {mean }} \cong \sigma / \sqrt{n} \frac{\sqrt{1+\varphi}}{\sqrt{1-\varphi}}$,

where $\sigma$ is the observed magnitude of variability of the observed differences in monthly averages, $\varphi$ is the observed autocorrelation in those differences and $n$ is the number of months of observed overlap. This estimate of standard error (SE) of the mean is dependent on the data behaving as an autoregressive with time lag of 1 month, AR(1), with the underlying interventions behaving approximately as a Gaussian distribution. This more appropriate formula gives a standard error on the mean of $5.2 \times 10^{-5} \mathrm{~W} \mathrm{~m}^{-2} \mathrm{~nm}^{-1}$, notably larger than if autocorrelation is ignored. Monthly averages have a broad range of uses in environmental sciences for trend detection, development of climatologies and monitoring the behavior of the Earth. Not only can monthly averages remove higher-frequency noise and some sampling matchup problems, but they can also obscure important details and can often introduce their own biases, especially when sampling is irregular in time or space (Toohey et al., 2013; Toohey and von Clarmann, 2013). We show the behavior of the underlying interventions as Gaussian and our tests for $\mathrm{AR}(1)$ in Appendix B.

We can invert the formula for the standard error on the mean in Eq. (1) and solve for $n$, resulting in the time to estimate the mean offset between two satellites for a given accuracy as

months to estimate an offset $\cong$

$$
1.96^{2} \sigma^{2} / \text { offset } \operatorname{limit}^{2} \frac{1+\varphi}{1-\varphi} \text {. }
$$

The above formula shows that, for a given magnitude of variability and autocorrelation in monthly satellite overlap data ( $\sigma$ and $\varphi$, respectively), the length of overlap needed is inversely proportional to the square of the accuracy desired for the offset estimate. The factor of 1.96 is to support a $95 \%$ confident limit on the offset with a $50 \%$ likelihood of detection; if more confidence is needed in the offset, a higher factor can be used based on classic statistical tables. Thus, if we can identify the level of uncertainty we can accept in a merged record due to the overlap offset $\left(\mathrm{SE}_{\text {mean }}\right)$, and if we have some understanding of the behavior of overlap differences $(\sigma$ and $\varphi$ ), either from advance estimates or from early analysis of offset data, then we can appropriately identify the length of overlap needed in a manner that is respectful of the inherent cost of added months of satellite overlap. If a higher level of certainty than $95 \%$ is required, the 1.96 factor is adjusted appropriately according to normal distribution tables. For a small number of months, the 1.96 will need to be adjusted for the Student $t$ distribution, which allows a larger uncertainty when a small number of points are used. With the example used in this paper and shown in Fig. 4, we observe a magnitude of variability, $\sigma$, 
of $1.7 \times 10^{-4} \mathrm{~W} \mathrm{~m}^{-2} \mathrm{~nm}^{-1}$ and autocorrelation, $\varphi$, of 0.89 . If we want an offset limit of $0.0008 \mathrm{~W} \mathrm{~m}^{-2} \mathrm{~nm}^{-1}$ (which is $1 \%$ of the mean of SOLSTICE during the overlap period), then the number of months would need to be 5 months using the Student $t$ distribution, which offers 2.8 as the appropriate factor in place of 1.96 . Note that to achieve the $95 \%$ confidence limit we must use the appropriate Student $t$ distribution, or approximately 1.96 multiplier in the large number limit, to assure we have the desired confidence in our overlap adjustment. Note also that this is a recursive effort because the answer, the number of months, is a function of the multiplier, which is itself a function of the number of months. This exercise is not overly onerous, because the formula offers an estimate of the length of time needed to limit uncertainty in an offset, and such an estimate is rarely precise to many significant digits. We conclude for the data sets we have been exposed to that after roughly 2 years of data collection the large number limit of 1.96 may be considered appropriate.

The impact of the offset on the use of the data is critically important to the final analysis. While a "best" merged data set may be produced from multiple satellites, users should never ignore the added uncertainty due to merged data sources. Using the merged data without including the impacts of the merging would result in smaller standard errors in computing means, variability in trends, than is actually appropriate. The magnitude of the impact of the offset correction is dependent on the use of the data. Two cases are considered here for illustrative purposes. If the merged data set is used to estimate the impact of storms on a stable electrical grid, and if the impacts have been estimated from the effects observed using the first satellite record, then an uncertainty of $0.2 \%$ means that the new solar storms may well be off by $\pm 0.2 \%$ and the uncertainty in impacts need to be appropriately calculated and conveyed. If the merged data sets are used to estimate long-term trends, then the impact of an uncertainty of $\pm 0.2 \%$ means that any trends derived will be affected by that level of uncertainty carried out through the length of the data set used for analysis and may affect the significance of the expected trend if care is not taken to reduce the uncertainty in the overlap adjustments.

\section{Drifts}

While offsets are routinely addressed in the merging of satellite data sets, potential drifts in satellite data are also critically important to many of the final applications of climate data, most notably trend detection both of the direct parameter being observed and observations that are dependent on the observed parameter. There are several fundamental factors that can contribute to a drift in satellite observations, including decay of instrumentation and changes in satellite orbit. Efforts are ongoing to minimize the impact of these factors, but all corrections involve assumptions, and each satellite may invoke different approaches to monitor and address stability.
The merging of satellite records, at a minimum, needs to test for potential drift between the overlapping satellite records. The amount of drift that can be detected through satellite overlap depends on the length of overlap period and on the quality of the matchup in overlapping data.

The impacts of undetected drift will have direct impact on the scientific results derived from the data. Bourassa et al. (2014) showed that the uncertainty in drift from a continuous record from multiple satellites is critical to longterm monitoring of the Earth. Rahpoe et al. (2015) find intercomparisons of six different ozone limb measurements to drift relative to each other at a statistically significant rate, sometimes as high as $5 \%$ decade $^{-1}$ or more. However, most drifts were statistically insignificant due to the limited length of data records - generally less than 10 years. In the case of solar-viewing instruments, BenMoussa et al. (2013) discuss in detail causes and effects of degradation in a variety of different instruments that span nearly 2 decades and cover a broad wavelength range. They conclude that there is no single best method to correct and monitor degradation and the correction schemes for overlapping missions are likely to be very different depending on the instrument hardware selection. An important example of this is well documented in the efforts to correct drift in the CIRES instrument (Cloud and Earth's Radiant Energy System; see Loeb et al., 2016, and references therein). In this report, long-term stability was linked to loss of optical transmission due to UV exposure and molecular contamination, very similar to the mechanisms discussed in BenMoussa et al. (2013). Fruit et al. (2002) have addressed the effects of energetic particles on glass transmission, but inhibiting and characterizing carbonization of optical surfaces remain a steadfast and unsolved problem. In each case, evaluation of how best to characterize the drift takes place. For the SOLSTICE-SIM data overlap, we noted that the differences between the two sets of data showed lower variability than the ratio of the data, indicating an offset would be better modeled as an additive adjustment. In many cases, uncertainty in satellite records' drift can be even more significant to scientific uses of the data than the offsets from one instrument to the next. In this paper, we look to see to what extent some confinement of the problem may be achieved through appropriate overlap of independent instruments.

If we can quantify the level of drift we would like to be able to detect, and if we can estimate the level of variability in the overlapping data, using approaches from Weatherhead et al. (1998), then we can estimate the length of time necessary to observe a drift of that magnitude in an overlapping data set. Weatherhead et al. $(1998,2000)$ have shown that one can estimate the length of time to detect trends in environmental observations. This approach is applied to estimate the time to measure a differential drift with a specified uncertainty in the observations taken by two different systems. When detection is considered at the $95 \%$ confidence level, estimated overlap 
for detection is

months to estimate a drift $\cong$

$$
12 \times\left[1.96 \frac{\sigma}{\mid \text { drift } \mid} \times \sqrt{\frac{1+\varphi}{1-\varphi}}\right]^{2 / 3},
$$

where |drift $\mid$ is the absolute value of the magnitude of the differential drift, and $\sigma$ and $\varphi$ are the magnitude of variability and autocorrelation, respectively, of the differenced monthly data once any existing trend is removed. We can identify the drift we would like to have the capability of detecting, and we estimate both $\sigma$ and $\varphi$ from existing data - either from observations or from modeled experiments. As an example, a drift of $0.1 \%$ per year of the observed SOLSTICE data $\left(0.00008 \mathrm{~W} \mathrm{~m}^{-2} \mathrm{~nm}^{-1} \mathrm{yr}^{-1}\right)$ with the observed variability in the overlap data (sigma of $8.59 \times 10^{-5} \mathrm{~W} \mathrm{~m}^{-2} \mathrm{~nm}^{-1}$ and phi of 0.57 ) results in 2.5 years likely needed to achieve that uncertainty.

It may be noted that the natural world has variability $(\sigma)$ and autocorrelation $(\varphi)$ that are inherent and may change slightly over time. A distinct advantage of satellite observations can be the frequency of the observations. MacDonald (2005) has shown that the monitoring approach can have a direct impact on these values, as well: monitoring less frequently - perhaps only once or twice a month - results in higher variability and slightly lower autocorrelation in our data set. As encapsulated in Eq. (1), an increase in the number of measurements per month improves the detectability (shortens the number of years to detect a given trend), but only up to the limit of the system's natural variability. For each situation of overlapping of satellite missions, the results will depend on the method of observation and the parameter being observed; for Earth observations, the results can also depend on location and even time of year.

Using the SOLSTICE-SIM data as an example, tremendous accuracy gains are achieved for each year of monitoring for the first few years of overlap, with diminished returns after that. When the cost of overlap is respected and appropriate calculations are made with emerging overlap data, an appropriate overlap plan can be estimated to allow for scientific standards to be met. Figure 5 shows that, for a given magnitude of variability and autocorrelation observed in overlap differences, we calculate the number of years of overlap needed to detect a specific level of drift. In this case, using the SOLSTICE-SIM data as an example, the magnitude of detectable linear drift drops from $1.1 \times 10^{-4}$ to $0.6 \times 10^{-4} \mathrm{~W} \mathrm{~m}^{-2} \mathrm{~nm}^{-1} \mathrm{yr}^{-1}$ by allowing the overlap to be 3 years, instead of 2 years. The level of agreement of data from the two instruments results in the magnitude of variability and autocorrelation observed in the differences. For observations that are very much in agreement with each other, we can expect low variability, and thus a relative drift can be detected earlier, as represented by the green lines in Fig. 5. For a poor match between the overlapping observations, we can

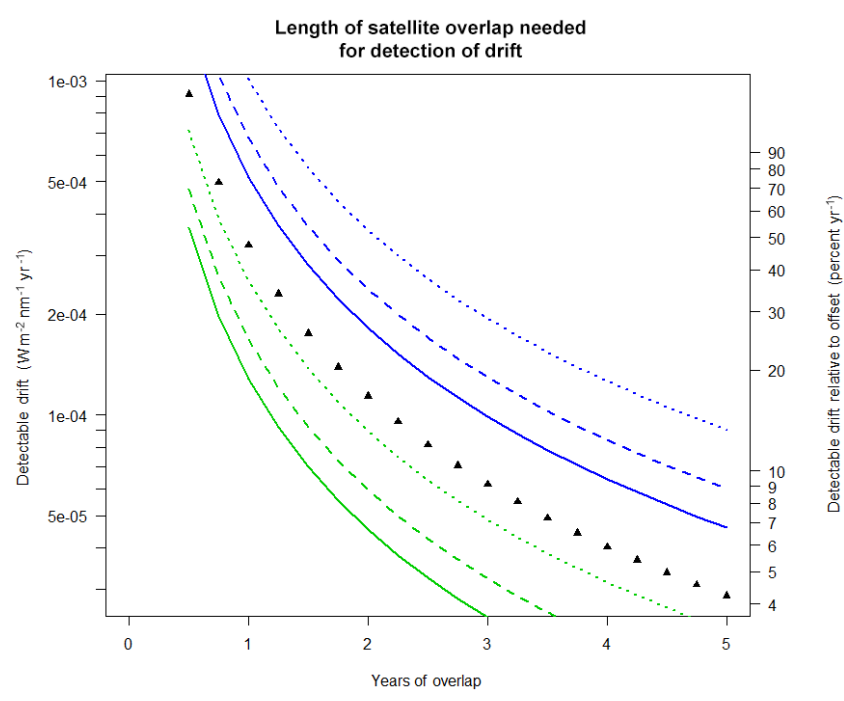

Figure 5. The ability to constrain a detectable drift is a direct function of the number of years of overlap and the quality of the overlap data. Black triangles offer the detectable drift in the difference between the SOLSTICE and SIM satellite instruments as a function of the overlap period; calculations made use of the observed characteristics of the SOLSTICE-SIM monthly differenced data: magnitude of variability of $8.58 \times 10^{-5} \mathrm{~W} \mathrm{~m}^{2} \mathrm{~nm}^{-1}$ and autocorrelation of 0.57 . Green lines assume a smaller magnitude of variability in the overlap data (half of what is observed in SOLSTICE-SIM) and autocorrelation of 0.4 (solid), 0.6 (dashed) and 0.8 (dotted). Blue lines assume a larger magnitude of variability in the overlap data (twice what is observed in SOLSTICE-SIM) and autocorrelation of 0.4 (solid), 0.6 (dashed) and 0.8 (dotted).

expect longer times of overlap will be needed as represented by the blue lines in Fig. 5. The relative drift on the right side of Fig. 5 offers information on the percentage basis of the overlap data, not in the raw SOLSTICE or SIM data sets, because it is the fundamental behavior of the differences that determines the information content of the overlap period. It is important to note that drifts in overlap data, as drifts in nature, can be approximated as linear, logarithmic or a variety of other representations, as the data and the physics of the situation suggest; for Fig. 5, we assume an approximately linear drift over the time period of the overlap. For satellite observations, a number of changes are expected over the life cycle of the instruments; all known and expected changes are approximated and adjusted based on current best understanding. However, particularly with new technologies, these assumptions must be checked by careful evaluation of the data, thus emphasizing the importance of an adequate overlap period to help confine potential drifts to a specified level. While pre-launch calibration may indicate drift will be less than a specific level, the ability to verify this will depend on independent intercomparisons of observations.

Although no error bars are offered in Fig. 5, it is important to remark that, when estimating how long it will take to 
detect a specified drift, two statistical levels must be considered: one that identifies the meaning of "detecting a drift" and a second that identifies the likelihood of detection of that drift in the specified period of time if that level of drift is the true, long-term drift in the overlap. Of course, it is possible to detect smaller drifts than the value obtained from any particular point (drift-overlap pair) of this figure, as it is also possible to determine a given drift a few months earlier or later than the value obtained from the point in the figure. Comments on the appropriate interpretation of the likelihood of drift detection are discussed in detail in Appendix C, where non-standard, two-dimensional error bars are introduced in the figure to help the reader to understand this uncertainty.

\section{Jumps}

Jumps are permanent or semi-permanent level shifts in the data that occur at specific points in time and are not attributable to the parameter being observed; jumps could represent a change in sensitivity of an instrument or a change in location or orientation of the satellite. To ignore such events results in greater uncertainty in the appropriate offsets and in artificial drifts in the final data set. If the magnitude and time of the shift are known, then the data can be adjusted before being analyzed for offsets and drifts. If the magnitude and timing of jumps are unknown, as is more often the case, and must be derived from the data, then the presence of such level shifts increases the uncertainty of both the offset and drift in the overlapping data and hence lengthens the time necessary to achieve a high-quality final data set. Continuous satellite overlap can make the ability to identify and understand sudden jumps significantly easier, but this is often beyond current monitoring approaches.

It is tempting to believe that jumps can be easily identified and corrected. Testing this belief, Free et al. (2002) carried out a comparison of seven different groups examining radiosonde records with the intent of identifying, quantifying and correcting observed discontinuities in temperature sonde time series. The different groups identified a widely different number of discontinuities using a range of techniques. They further differed significantly on the magnitude of corrections and even, at times, the sign of the needed correction, resulting in changes to observed trends by between 35 and $80 \%$. Thus, even identified and corrected discontinuities introduce some uncertainty in the long-term stability of the record. Weatherhead et al. (1998) showed that these corrections can be quantified with advanced statistical techniques. The resulting uncertainty in long-term stability increases the number of years necessary to detect trends, independent of how large the correction is. Hurrell and Trenberth (1997) point to the importance of two small, discrete, downward jumps in merged satellite records that dominated the trend results for tropospheric temperature records.
Jumps can occur for a variety of reasons related to instrument changes (e.g., Brown, 2013). Depending on the physical source of the jumps, the effects can last from less than a few hours to multiple years. In some cases, true jumps occur in the parameter being observed. In many other situations, the observing system or assumptions used in the algorithms are responsible for the jumps and there is a desire to identify and remove these spurious jumps. The statistical removal of a spurious jump involves two steps: identifying a jump in the overlap differenced data and estimating the magnitude of the needed correction. A variety of approaches are used to both identify jumps (Jaxk et al., 2007; Vincent et al., 1998; Vincent et al., 2002; Ducre'-Robitaille et al., 2003) and correct for these jumps in satellite and non-satellite observing systems (Karl and Williams, 1987; Mitchell and Jones, 2005). When information is available to identify the timing of a jump, there is considerably more confidence in the correction for the jump because physical interpretation is easier and therefore corrections can be physically based rather than statistically based. If there is no external information on timing, then one has to consider that there could be other jumps below the threshold for detection, and estimates for how the instrument is behaving are more uncertain. For jumps in overlapping data sets, the correction brings into question the magnitude of any derived offset as well as the magnitude of any drift in the overlap period. For jumps in observing systems when there is no overlap, the challenge of appropriately identifying and correcting jumps is notably more difficult, again pointing to the value of redundant observing systems when possible. We focus on the ability to detect and understand the jumps that last more than a few months, as they may be the interruptions that can cause the most serious damage to longterm records, particularly those used in the context of climate research. We consider the two cases separately of how a jump affects the offset estimate and how a jump affects the drift estimate.

While ancillary data about the instrument or the observed parameter may be used to identify the existence and timing of a jump, deriving the magnitude of correction by examining the data is dependent on the amount of variability (both magnitude and autocorrelation) in the overlap difference data. For the case of an otherwise stable offset between the two sets of satellite data, the added uncertainty in the true offset is enhanced based on the uncertainty of the jump. The impact of the jump on offset estimates is a minimum when the offset occurs in the middle of the overlap period, because maximum information is available to identify the size of the jump. For the case of a drifting offset between the two sets of satellite data, the added uncertainty in the true drift is also enhanced based on the timing of the jump. Because the impact of the jump is colinear with the derived drift, estimating the overall drift in instrument offset is more difficult in the presence of jumps. We assume that we are going to fit the environmental 
data to a linear statistical model of the form

environmental data $=$ mean + linear $\mathrm{drift}$

$$
+ \text { offset }_{\tau}+\text { noise }(0,1) \text {, }
$$

where the mean, linear drift and offset at time $\tau$ are derived from the data. The residuals (noise $(0,1))$ are modeled as an $\mathrm{AR}(1)$ process with mean $=0$, and both $\sigma$ and $\varphi$ derived from the observations. With such a statistical model, Weatherhead et al. (1998) show that the impact of the additional jump term on deriving an accurate estimate of drift is dependent on the timing of the jump.

Months to estimate a drift $\cong$

$$
12 \times\left[1.96 \frac{\sigma}{|\mathrm{drift}|} \times \sqrt{\frac{1+\varphi}{1-\varphi}}\right]^{2 / 3} \frac{1}{[1-3 \tau(1-\tau)]^{1 / 3}},
$$

where $\tau$ is the fraction of the data before the identified jump occurs. Thus, a longer time of overlap is required for accurately confining a drift in overlap data: as opposed to the impact of jumps on estimating offsets, the impact of jumps on derived drifts is largest when the jump occurs in the middle of the overlap period ( $\tau=0.5$ ), where the amount of time is increased by a factor of 1.59. This increase in the length of time needed to estimate a drift is due to the similar temporal signature of both drifts and jumps on a long-term record as illustrated in Fig. 6. Equation (4) assumes that any drift and offset will be fitted to the data simultaneously. If data are fitted sequentially to an offset and then to a drift, the derived drift will be considerably smaller than if the data were fitted to a drift and then to an offset because the two functions (drift and offset) are not orthogonal, and thus the derived results for magnitude of offset and magnitude of drift are not commutative. To be explicitly clear, correction of offsets in advance of deriving drifts can artificially minimize the amount of observed drift, while ignoring offsets (perhaps because they are not easily detectable) can either add to or diminish the derived drift.

In the case of the SORCE instruments, these jumps are mostly prompted by changes in the performance of hardware subsystems of the spectrometers. For example, a significant jump occurred in the SIM on 14 May 2007 related to the instrument becoming very cold during a safehold event, and upon recovery the instrument did not return to the same state as before the safehold. This event produced a significant change in the hardware that controls the wavelength drive (see Harder et al., 2005a, for a description of the wavelength drive mechanism). Even after the wavelength correction a residual jump in irradiance level was still observed; the most likely cause of this jump is a change in light transmission caused by a change in optical path through the instrument that is different than before the safehold event.

For the particular case of Fig. 3, the jump appears to be adequately corrected, but other wavelengths show a discernable discontinuity. A similar observation can be made about
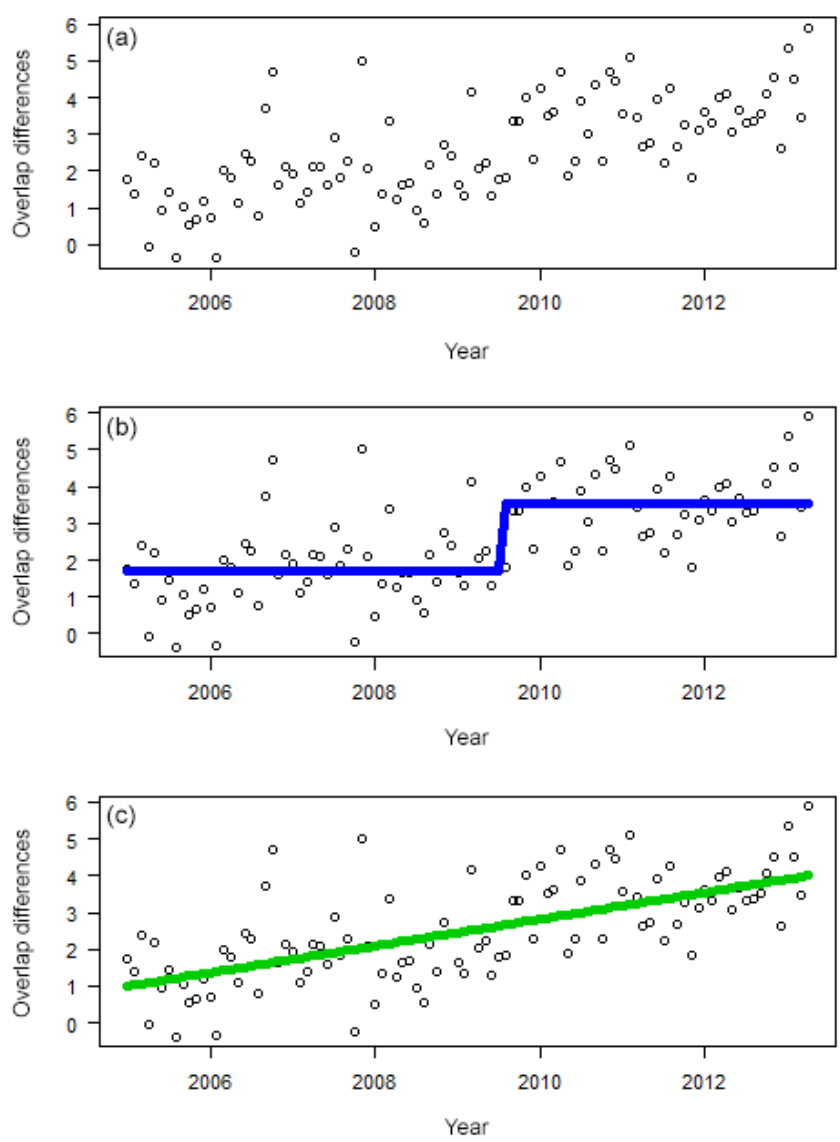

Figure 6. This data set was created to visually show the potential impact of a spurious jump on the estimate of offsets and drifts. In all three plots, the same data are shown, with the second plot showing how the data could be modeled as an offset. The data were actually created by adding a linear drift to simulated autoregressive data, as shown in the third plot. The confounding nature of jumps and drifts cannot easily be separated, although ancillary data can be extremely helpful. Note these are synthetic data with arbitrary units.

the SOLSTICE slit anomaly in 2006 (see Fig. 3). Most disconcerting about these events is the possibility that the jumps can be disguised as a change in stability and produce results similar to what appears in the discussion of Fig. 6.

\section{Impacts of uncertainty in drifts}

The primary purpose of overlap in instruments is to understand how two different instruments are responding to the parameter each is intended to measure. Uncertainty in the long-term stability of data products directly affects the level of confidence one can have in the long-term, merged data sets. Logan et al. (2012) noted that differences as small as a few parts per billion in ozone records with 2-3 of years overlap lead to different trends for 1995-2008. Frith et al. (2014) use Monte Carlo techniques to estimate the uncertainty of the 
SBUV MOD merged data set based on both overlap information and validation against independent data sets.

The impact of undetected drifts in overlapping data sets on the merged record can be illustrated with a simple Monte Carlo representation, as shown in Fig. 7. Consider two satellites launched with 7-year lifetimes. The second satellite (blue trace) overlaps the first satellite (green trace) by either 1 or 2 years (top plot and bottom plot, respectively). Each satellite launches with an uncertainty estimate of the pre-flight absolute calibration of its measurements and some level of unidentified drift in the instrumental record, acknowledging that all identified drifting factors have already been corrected to the best abilities of the instrument team. For this illustration, we assume our simulated instruments have the same variability and autocorrelation during their overlap as the SOLSTICE-SIM data used in the previous sections. Accordingly, an overlap of 1 year implies a drift in the differences smaller than $3.28 e^{-4} \mathrm{~W} \mathrm{~m}^{-2} \mathrm{~nm}^{-1} \mathrm{yr}^{-1}$ (1 standard deviation, roughly $48 \% \mathrm{yr}^{-1}$ ) would be undetectable, and a relative drift of $1.16 e^{-4} \mathrm{~W} \mathrm{~m}^{-2} \mathrm{~nm}^{-1} \mathrm{yr}^{-1}$ (1 standard deviation, roughly $17 \% \mathrm{yr}^{-1}$ ) would be undetectable with 2 years of overlap (see Fig. 5). For illustrative purposes we show 100 simulations generated based on these potential relative drift values. In addition we depict a scenario in which the prelaunch absolute calibration of the second instrument is better constrained, which can occur when advanced technologies are introduced. Such a priori information about the individual data sets is important; in this case a user might choose to adjust the first satellite record to the second to take advantage of the smaller absolute uncertainty in the second instrument.

We note that the drift uncertainty depicted here only represents the uncertainty associated with adjusting one data set to the other; it does not include the absolute drift. If, as an example, we assume our two simulated instruments had the same relative drift as observed in the SOLSTICE-SIM example ( $\sim 1.67 e^{-4} \mathrm{~W} \mathrm{~m}^{-2} \mathrm{~nm}^{-1} \mathrm{yr}^{-1}$; see Fig. 4), this drift is not detectable with 1 year of overlap but is detectable with 2 years of overlap. However no amount of overlap can reduce the true absolute drift of either satellite data set. As with any instrument intercomparison, satellite overlap by itself cannot replace calibration, but it does offer valuable information that significantly complements all other available information. However, this illustration can help guide how large an impact any confinement of potential drift may be and can offer insights into whether uncertainty in the level of drift is too large for the intended use of the data. Based on this type of analysis, some have argued for the value of redundancy in observing systems (Weber et al., 2016b) and the value of continued replacement of satellites to minimize the extent of unchecked drift in a single record (Stolarski and Frith, 2006; Frith et al., 2014; Weber et al., 2016a) to potentially reduce the absolute uncertainty in merged records.

\section{Application to in situ and ground-based observations}

Both in situ and ground-based Earth observations often require targeted efforts and planning to assure a continuous record based on discontinuous observing systems. In some cases, overlap is impossible when changes take place - for instance when an expensive instrument moves location within a region or local changes, such as urban development, directly affect the local observations. However, in some cases, the approaches presented in this paper can have direct relevance. The WMO's Global Climate Observing System's Reference Upper-Air Network (GRUAN) is currently evaluating the transition from one sonde instrument package to another. Such a change in instrumentation is likely to affect the data stream particularly when extreme values are concerned. The planned overlap period and detailed planning of the intercomparison of results are currently underway within the GRUAN leadership team. In a similar situations, the UK Met Office evaluated the impact on a the switch from RS92 sondes to RS41 sondes, following a careful study carried out jointly with Vaisala and the UK Met Office making use of simultaneous launches of 30 sets of two RS92 and two RS41 launches. The ability to compare the data simultaneously using the same balloon system and doing the intercomparisons with synchronized GPS times allowed for much smaller differences in the statistical limit to be placed on the impact of transition from the RS92 to RS41 observations. This controlled study is the ideal situation and contrasts with no overlap as noted by Weatherhead et al. (1997), who showed the large impact of sudden shifts of radiation measurements, some of which were due to shadowing of the instruments by newly built structures. The sudden shifts without overlap rendered the data inappropriate for trend analysis because the uncertainty due to the level shifts were too large to allow detection of trends expected from ozone loss.

\section{Optimization and economic benefit}

Decisions to improve a single observing system can rarely be made without consideration of the potential impact on the support of other approaches to improve monitoring. Figure 5 shows that drift detection accuracy improves as the number of overlap years increases. Improvements in drift detection capability decrease as the number of overlap years increases, but the optimal overlap duration is difficult to identify unless restrictions, such as cost, are considered. If a specific stability criterion is the objective, the minimum required overlap can be directly determined to meet that criterion. Assuming that the total costs increase as overlap time increases (this value can often be in excess of USD 1-2 million per year), from an economic perspective the minimum required overlap time should also be chosen as the most cost-effective. Although technical criteria are critical to understanding optimal data series overlap, decisions in the policy arena are often 


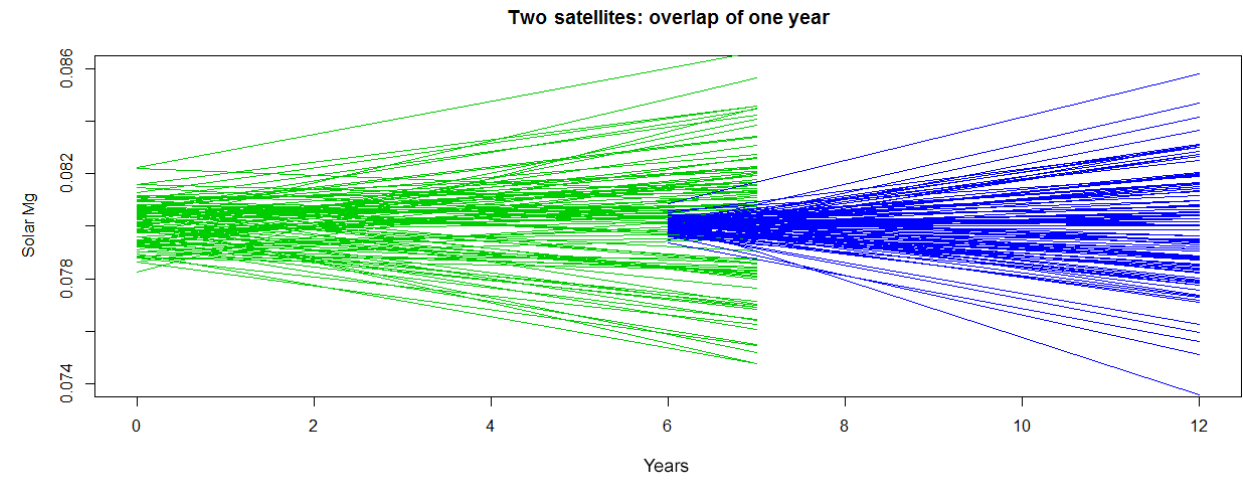

Two satellites: overlap of two years

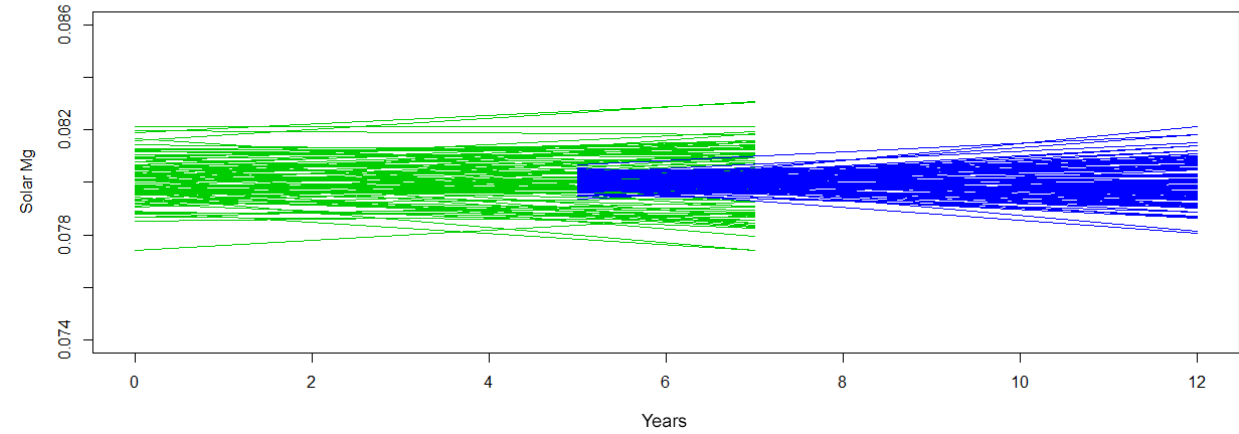

Figure 7. Two overlapping satellite observations (shown in green and blue) simulating $280 \mathrm{~nm} \mathrm{Mg} \mathrm{II} \mathrm{irradiance}\left(\mathrm{W} \mathrm{m}^{-2} \mathrm{~nm}^{-1}\right) \mathrm{with}^{\text {an }}$ expectation for some absolute pre-flight calibration uncertainty and some unidentified on-orbit drift. The amount of unidentified drift can be estimated in the overlap period, resulting in the possibility of a correction to the data. The uncertainty in the estimate of the drift is notably smaller with a 2-year overlap period in satellites compared to a 1-year overlap.

based on economic analysis, and thus it is important to better understand how economic analysis frames the allocations of resources. "Optimal" in such discussions is structured on criteria measured in societal benefits and costs.

In addition to overlap time, a number of choices may be proposed to improve observational climate records, including, as already mentioned, improved pre-calibration of satellite systems, intra-satellite calibration mechanisms, redundancy in observing systems and campaign verification of observations. In considering any proposed set of approaches to achieve a specific stability criterion, the least cost option or combination of options should be chosen. However stability criteria are often not available or substantiated. Under the constraint of fixed budgets, and without specific criteria, the maximum overlap period affordable would be optimal. If there are multiple approaches being considered, the combination of improvement approaches to achieve the greatest stability in the data within the exogenously determined budget would be optimal. Given the complementary information in various approaches to improve both absolute and relative calibration, linear optimization approaches may need to be developed to identify the best mix to achieve optimal calibration.
Without specific stability criteria or budget constraints, economic criteria suggest choosing the overlap period or combination of approaches to achieving data stability that provides the maximum net societal benefit (i.e., total benefits minus total costs). ${ }^{2}$ Identifying the societally optimal choice implies choosing the overlap (or possible mix of calibration methods) where marginal cost equals marginal benefits. Marginal costs are the change in program costs to achieve one unit of improvement (e.g., $\mathrm{W} \mathrm{m}^{-2} \mathrm{~nm}^{-1} \mathrm{yr}^{-1}$ in detectable drift as per Fig. 5). From an economic perspective, the marginal benefits of one unit of improvement in the data quality should be measured in terms of potential changes in societal outcomes from the use of improved information (a value-of-information, or VOI, approach; Laxminarayan and Macauley, 2012). While there has been some work on the value of information from satellites (Donaldson and Storeygard, 2016; Cooke et al., 2014; Macauley, 2006), there have not been many applications of economic analysis to determine optimal observational systems. Morss et al. (2005) provide an overview of relevant economic concepts and theory

\footnotetext{
${ }^{2}$ Appendix D provides a more technical explanation of the optimal choices under difference decision situations from an economic perspective.
} 
for optimal design of observational systems based on costbenefit trade-offs.

Given the limited number of applied studies on societal benefits of satellite data, standard approaches would need to be adapted to further understand the value of stable records and develop the decision-making tools to optimize observation systems. Weatherhead et al. (2015) have gathered community input to help identify key science questions that need to be addressed, while Feldman et al. (2015) have outlined some tools for assuring observing systems can meet these approaches. The general field of climate observing system simulation experiments (C-OSSEs) is gaining serious attention from both scientists and science managers internationally.

This paper provides guidelines for what may be considered idealized situations. Approximations have been made about the linear nature of drifts and timescales of jumps that are likely approximations to considerably more complicated instrumental response. Individual judgment is needed to apply the results from this paper as instrument characteristics often change over time and principal investigators will often have additional information that will guide their decisions about the quality and stability of instruments. Ground-based instruments would likely add further information to help evaluate stability. Notably, the beginning and end of most satellite missions are the periods where most challenges occur in the instruments and may alter the guidelines presented here. As an example, instruments behaving very badly are perhaps not of sufficient quality to contribute useful information, and less overlap would be needed. Much of this uncertainty points to the value of redundancy of sensors and the value of complementary observing approaches, despite their potentially high cost.

While economists have extensive experience and applications in monetizing the value of potential changes in societal outcomes (e.g., lives saved, reduced damages, improved crop yields), it is generally much more difficult and thus important to build more applications (1) identifying all of the potential stakeholders and potential outcomes and (2) validly and reliably characterizing and quantifying the information value chain and how it changes.

\section{Conclusions}

We acknowledge, as many colleagues before us (e.g., WMO, 2011a; Wulfmeyer et al., 2015; Ohring et al., 2005; Wielicki et al., 2013), the importance of a continuous satellite record to understand solar and planetary behavior. In this paper we focus on the development of a relatively stable data record, making full use of available satellite data, as opposed to calibration efforts to allow a traceable record of absolute accuracy. We examine three aspects for the merging of satellite data: identifying and quantifying an offset between two satellite records, estimating drifts between two satellite records, and understanding the impacts of sudden changes in the data records on both offset and drift estimates. For studies making direct use of the satellite data, either to develop a continuous record or verify the stability of a record, the most direct control available in an observing strategy is to control the length of overlap in the satellite records. We identify the impact of length of time of overlap on all three of these aspects of merging satellite data and illustrate these approaches with data from two instruments used to observe solar output.

The uncertainty due to the merging of satellite records is unavoidable, but quantification of this uncertainty is possible. In the case of identifying or verifying the offset in two satellite records, the uncertainty is inversely proportional to the square root of the number of months of overlap. In the case of identifying or verifying the long-term relative stability or potential drift, the number of months of overlap is inversely proportional to the drift to the $2 / 3$ power. Both time estimates require some understanding of the variability in the overlap differences. If no estimate of overlap variability is available, the behavior of the first few months of overlap can be evaluated to estimate the length of overlap needed to achieve the prescribed tolerance. The impact of abrupt disruptions in the overlap period on offsets can require up to $50 \%$ more overlap to be able to identify the offset and drift with the same level of tolerance.

These algorithms are appropriate for a direct evaluation using only the satellite data. In some cases, particularly with Earth observations, added benefits and challenges may exist. For instance, with Earth observations, additional in situ and ground-based observations may be available to reduce uncertainty in satellite overlap. However, a challenge to Earth observations is the need for direct temporal and spatial overlap, which can be difficult or impossible as satellite observation approaches are considered within challenging budgetary constraints. All of the techniques outlined here can be applied to identifying the level of overlap needed with existing satellite observations and next-generation observations or reference calibration satellites, such as proposed by CLARREO. In all cases, the level of uncertainty in offsets and drifts will be determined not by the length of overlap but in the quality of the matchup between the reference and operational satellites. Under various constraints, choices of overlap can be optimized to help assure climate records that are appropriate for advancing our understanding of the Earth system. The goal of achieving the most stable observational data from existing and future observations is fundamental to understanding the Earth and potential long-term changes. The value of this paper is the ability to estimate, either prior to satellite launch or soon after satellite launch, the amount of time needed to achieve or verify tolerance for a stable merged satellite record using objective criteria.

Code and data availability. Example data and code used will be available from the first author on request (betsy.weatherhead@colorado.edu). 


\section{Appendix A: Comments on the usefulness of monthly data}

The use of monthly averaged data has been common in climate studies for many years, despite obvious deficiencies in this somewhat arbitrary choice. One deficiency is in weighting a daily value in February more highly than a daily value from any other month simply because February has fewer days than, for instance, May. A second deficiency is the lack of matchup from the monthly time frame to the natural world: the summer solstice is not in the center of June but off-center, meaning that the June average would contain more information on pre- than on post-solstice conditions. Even nonscientific users of climate data are used to using reports such as "Climatic Normals, World Weather Records, and Monthly Climatic Data for the World" for useful information. WMO's Guide to Climatological Practices even suggests, "Caution is needed when data are in sub-monthly resolution..." and makes considerable effort to coordinate climate data in a standardized manner (WMO/TD 341, 1989).

These issues are admittedly not likely of great importance, but for the reader who appreciates a great deal of caution with respect to the use of data we offer this simple examination of the impact of monthly averages in the context of the algorithms presented in this paper. For the example data set used in this work, a more natural timescale is the Carrington rotation rate of 27.2753 days. For the small study presented in this appendix, we examine how the results of this paper would have differed if we had used the data averaged in 27day periods as opposed to using the data averaged by month.

The change in values from monthly values to solar rotation values, the mean, standard deviation, standard error on the mean and autocorrelation change very little.

For calculations of detecting an offset, the magnitude of variability and autocorrelation of the data were used; for the calculations of detecting a drift, the magnitude of variability and autocorrelation of the detrended data were used. The calculations for a small number of months in the final column are adjusted from a factor of 1.96 to 2.8 to account for the uncertainty in the small sample size. We note that the differences observed are remarkably small. Differences likely would have been larger if we had used data of a shorter duration (e.g., 2 years of data instead of just over 3 years). One note is that, when the solar rotation period is used for averaging, 42 data points are derived, as opposed to the 39 data points derived from monthly averages. This "larger number" of data points is accompanied by a slightly lower standard deviation and nearly constant autocorrelation and directly feeds into the standard error calculation.

\section{Appendix B: Comments on the applicability of estimation of number of years of overlap}

For many statistical analyses commonly carried out in climate research, data are assumed to be near-Gaussian and independent (each value is independent of the others). For environmental data, monthly averaged data are often assumed to be autocorrelated with a lag of 1 month in such a manner that an AR(1) model can adequately describe the behavior of the data once seasonal aspects are removed. As a reminder, the number of years needed to detect an offset is estimated as

months to estimate an offset $\cong$

$$
1.96^{2} \sigma^{2} / \text { offset limit }^{2} \frac{1+\varphi}{1-\varphi},
$$

and the number of years of overlap to detect a drift is estimated as

months to estimate a drift $\cong$

$$
12 \times\left[1.96 \frac{\sigma}{\mid \text { trend } \mid} \times \sqrt{\frac{1+\varphi}{1-\varphi}}\right]^{2 / 3},
$$

with $\sigma$ and $\varphi$ as the monthly standard deviation and autocorrelation as described in the body of the paper. Because the estimate of the number of years is dependent on these assumptions, we explicitly test the data used as an example in this paper for illustrative purposes.

The autocorrelation, $\varphi$, is the most difficult parameter to estimate accurately in a time series, particularly when $\varphi$ is large. In the case of large autocorrelation, the time series can differ from the long-term mean for many months; if the estimate of phi is made from a small number of points, the sample estimate of phi can be off, but the standard deviation and mean can also be far from representative.

In situations of high autocorrelation ( 0.7 in the top plot of Fig. B1), a time series can deviate from the long-term mean ( 0 in both of these simulated time series) for many months. If a short time period is used to estimate phi, likely phi will be underestimated, and the error on the sample mean may be farther from the true population mean than for a situation with low autocorrelation (0.2 in the bottom plot of Fig. B1). For the data used in this paper, the autocorrelation is estimated at 0.1 once drifts are accounted for, and therefore the overlap period of 6 years is more than adequate to derive a good estimate for the long-term value of phi. To test for AR(1) behavior in the SOLSTICE-SIM monthly overlap data, we calculate a partial autocorrelation function out to 15 terms.

Figure B2 shows both an autocorrelation function (ACF) for the SOLSTICE-SIM data (top plot) and a partial autocorrelation function (PACF) for the SOLSTICE-SIM data (bottom plot). The plots allow confirmation that the residuals of the data behave as an AR(1) process: the ACF shows significant autocorrelation for a lag of 2 months; the PACF shows 
Table A1. Fundamental descriptive values and calculations of overlap periods were calculated using monthly averaged data and data that were averaged over a 27-day time period, which is a more natural time frame for these calculations. We note that little impact is observed from this small change in averaging period.

\begin{tabular}{|c|c|c|c|c|c|c|c|}
\hline & $\begin{array}{r}\text { Mean } \\
\left(\mathrm{W} \mathrm{m}^{-2} \mathrm{~nm}^{-1}\right)\end{array}$ & $\begin{array}{l}\text { Standard deviation } \\
\qquad\left(\mathrm{W} \mathrm{m}^{-2} \mathrm{~nm}^{-1}\right)\end{array}$ & Autocorrelation & $\begin{array}{r}\text { Standard deviation } \\
\text { detrended data } \\
\left(\mathrm{W} \mathrm{m}^{-2} \mathrm{~nm}^{-1}\right)\end{array}$ & $\begin{array}{r}\text { Autocorrelation } \\
\text { of detrended } \\
\text { Data }\end{array}$ & $\begin{array}{r}\text { Time periods (months or } \\
\text { solar rotation cycles) to } \\
\text { identify an offset of } \\
0.0008 \mathrm{~W} \mathrm{~m}^{-2} \mathrm{~nm}^{-1}\end{array}$ & $\begin{array}{r}\text { Years to identify } \\
\text { a drift of } 0.00008 \\
\mathrm{~W} \mathrm{~m}^{-2} \mathrm{~nm}^{-1} \mathrm{yr}^{-1}\end{array}$ \\
\hline \multicolumn{8}{|l|}{ SIM } \\
\hline Monthly & 0.07839 & $4.78 \times 10^{-4}$ & 0.939 & $1.528 \times 10^{-4}$ & 0.429 & 43.6 & 3.27 \\
\hline Solar & 0.07837 & $4.70 \times 10^{-4}$ & 0.945 & $1.499 \times 10^{-4}$ & 0.460 & 47.0 & 3.31 \\
\hline \multicolumn{8}{|c|}{ SOLSTICE } \\
\hline Monthly & 0.07907 & $3.55 \times 10^{-4}$ & 0.890 & $1.733 \times 10^{-4}$ & 0.544 & 13.0 & 3.94 \\
\hline Solar & 0.07905 & $3.41 \times 10^{-4}$ & 0.898 & $1.639 \times 10^{-4}$ & 0.533 & 12.9 & 3.75 \\
\hline \multicolumn{8}{|c|}{ SOLSTICE-SIM } \\
\hline Monthly & $6.802 \times 10^{-4}$ & $1.67 \times 10^{-4}$ & 0.890 & $8.586 \times 10^{-5}$ & 0.570 & 4.94 & 2.52 \\
\hline Solar & $6.831 \times 10^{-4}$ & $1.69 \times 10^{-4}$ & 0.901 & $8.363 \times 10^{-5}$ & 0.609 & 5.70 & 2.58 \\
\hline
\end{tabular}
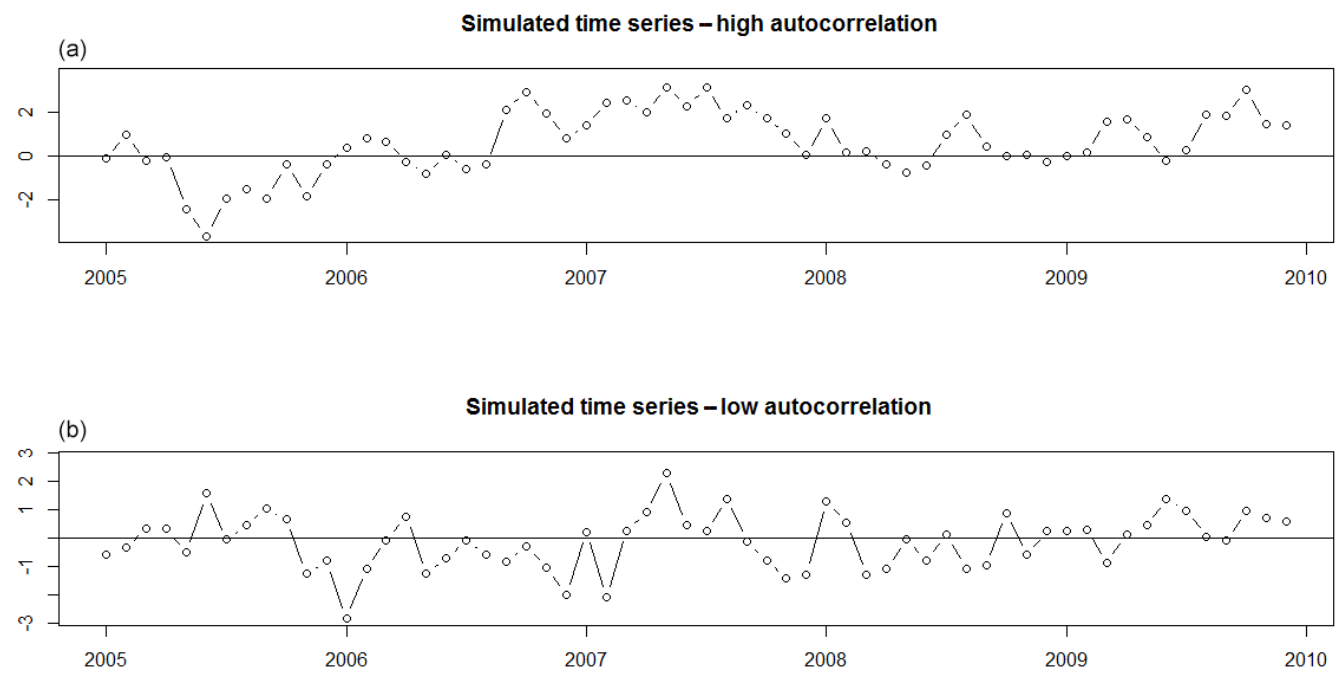

Figure B1. Two simulated time series are shown with high autocorrelation (a) and low autocorrelation (b).

that there is no significant correlation once a lag 1 correlation is accounted for. The standard deviation, $\sigma$, is assumed to represent the spread of Gaussian or normal distribution. The standard deviation calculation can be carried out on any distribution and can be both informative and useful for many distributions. For the "number-of-years" estimate to be appropriate, the assumption is that the standard deviation represents the spread in a Gaussian distribution. For the $\operatorname{AR}(1)$ case, the test for Gaussian behavior is performed on the underlying interventions in the $\mathrm{AR}(1)$ process, which is similar to, but not identical to, the residuals observed in the overlapped data. To test for Gaussian behavior, we compare our data to a standard Gaussian distribution in a $Q-Q$ plot (e.g., Hamilton, 1994; Box et al., 2015):

$Q-Q$ plots, such as those shown in Fig. B3, compare the distribution from a pure Gaussian distribution to the distribution of deseasonalized data used in this study. The roughly linear relationship demonstrated in the $Q-Q$ plots of Fig. B3 shows that the three data sets do behave in a closeto-Gaussian nature, and thus the use of Eqs. (2) and (3) are supported for the analyses presented in this paper.

\section{Appendix C: Comments on the interpretation of time estimates}

Any estimate of how long it will take to correctly identify a drift must be taken with some level of understanding of how this estimate is made and what can be expected from using these estimates. Figure 5 offers estimates for a range of times needed to estimate specific drifts, assuming no jumps occur in the record. As a reminder, this plot was created assuming the type of overlap seen in the SOLSTICE-SIM overlap period; specifically, the calculations assume the amount 


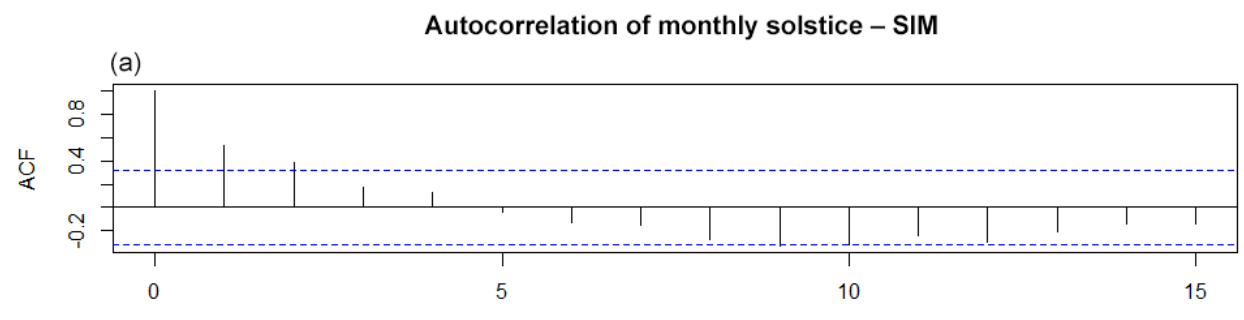

Lag

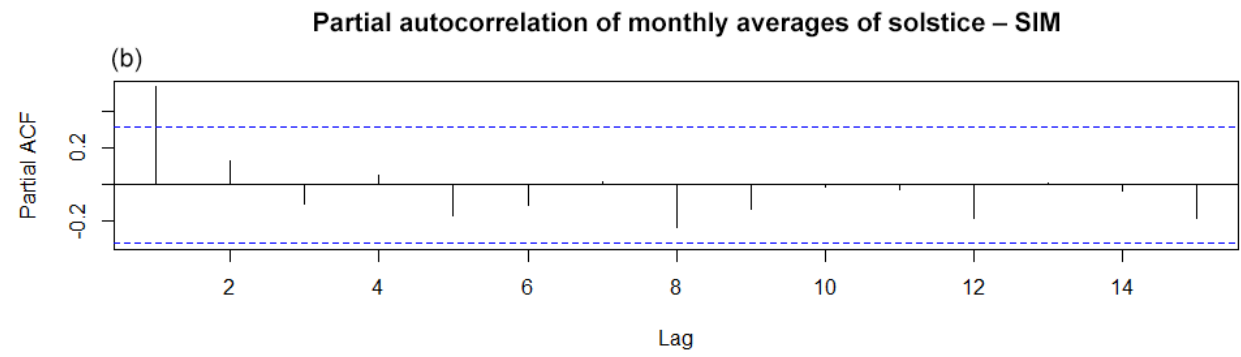

Figure B2. The autocorrelation function results and partial autocorrelation function results support the temporal behavior of an AR(1) statistical model and therefore support the use of both Eqs. (2) and (3) in the body of the paper. The dashed blue lines indicate thresholds of statistical significance for results. Each lag for this data set represents calculations based on differences of 1 month.
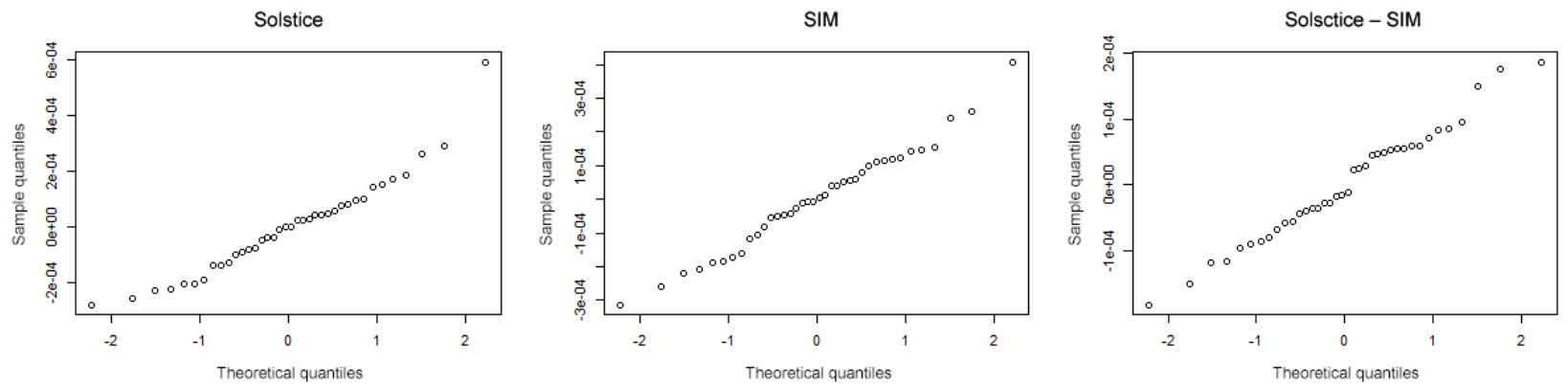

Figure B3. These three $Q-Q$ plots compare the monthly averaged SOLSTICE, SIM and SOLSTICE-SIM differences to theoretical Gaussian distributions.

of variability and autocorrelation observed in the differences (shown in the second plot of Fig. 4). However, different observing systems are likely to have different levels of agreement.

When deriving drifts on existing data, only a single level of certainty is required: for example, what does it mean to detect a drift? Often the community has focused on detection at a $95 \%$ confidence level or a $99 \%$ confidence level. However, when estimating how long it will take to detect a drift, two statistical levels are required: one that identifies what is meant by "detecting a drift" and one that identifies the likelihood that a drift will be detected in the specified period of time if that level of drift is the true, long-term drift in the overlap. For the first, we consider detecting a drift to mean identifying a drift that, with $95 \%$ likelihood, is not zero, although other levels may be considered. For the second, we consider the likelihood of detecting the drift (at the $95 \%$ confidence level) to be $50 \%$. To be clear, we may detect the drift, if it is real, a few months earlier or a few months later than the estimated time.

There are no error bars in Fig. 5. We would like to begin the discussion of appropriate error bars in this section. As stated in the previous paragraph, the data in Fig. 5 represent estimates of how long it will take to detect a specific level of drift. If we focus on a single point, for instance the 2-year point that indicates a drift of $1.2 \times 10^{-4} \mathrm{~W} \mathrm{~m}^{-2} \mathrm{~nm}^{-1} \mathrm{yr}^{-1}$ could be detected, it is possible that a slightly smaller drift could be detected in that 2-year period of overlap if the variability happens to result in a signal-to-noise ratio for the overlap period that is slightly more favorable. Similarly, if the actual underlying drift is actually 5 times as large $\left(6 \times 10^{-4} \mathrm{~W} \mathrm{~m}^{-2} \mathrm{~nm}^{-1} \mathrm{yr}^{-1}\right)$, it is highly likely the drift would be detectable within the 2 years. So the "error bars" on this one point would be slightly below the current point and would extend infinitely upward, indicating that much larger drifts could be detected in the 2-year period. 

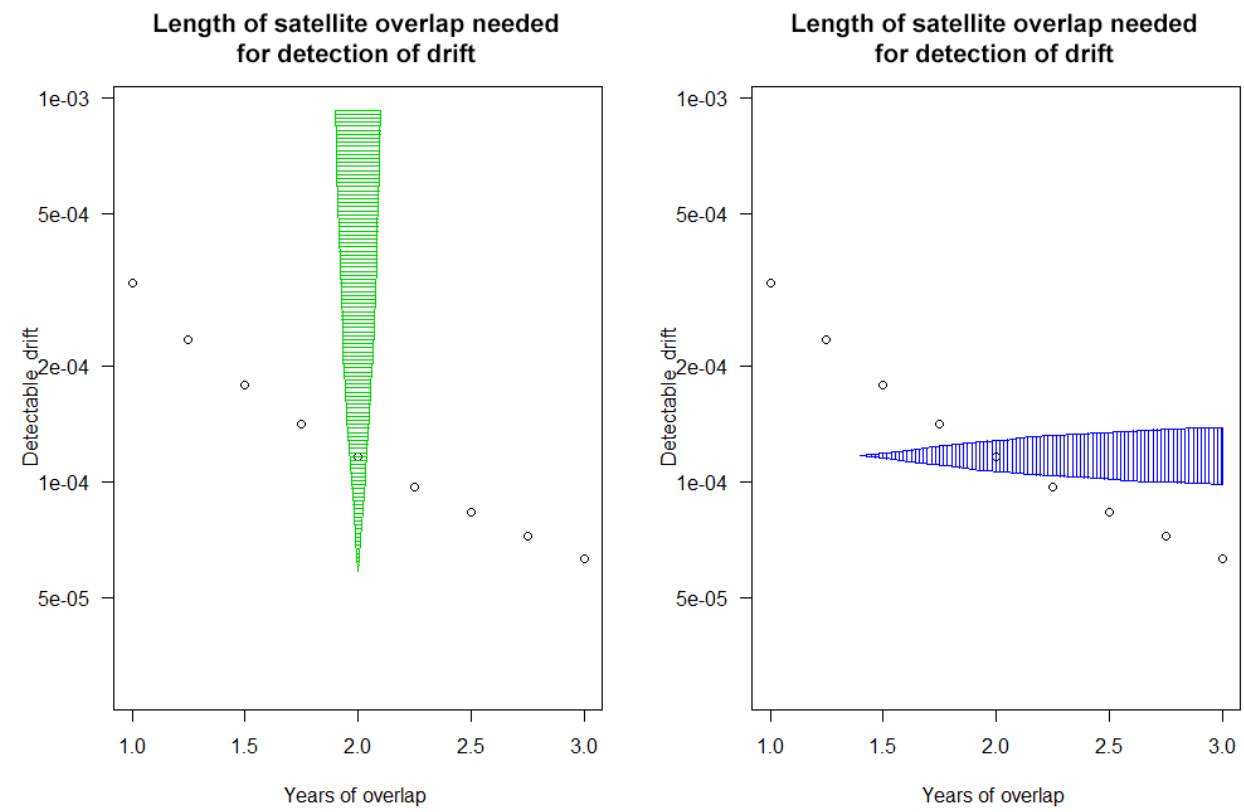

Figure C1. Estimates of how long it will take to detect a drift can be interpreted as the likely time needed. Depending on variability present, even small drifts can be detected (albeit with less than $50 \%$ likelihood of detection), with probability indicated by the width of the green area. For a given drift level, there is a chance that the drift can be detected in less than the number of years indicated, although that likelihood is less than $50 \%$ for time less than the times indicated; the probability is indicated by the blue area.

Extending our discussion of error bars in Fig. 5, we can similarly think in terms of horizontal error bars. Again, focusing on the one point in Fig. 3 indicating that a drift of $1.2 \times 10^{-4} \mathrm{~W} \mathrm{~m}^{-2} \mathrm{~nm}^{-1} \mathrm{yr}^{-1}$ could be detected in 2 years, this drift, if it is the true underlying drift, may be detectable a few months shy of 2 years or may take a few months more than 2 years. As stated above, at 2 years there is a $50 \%$ likelihood of detection. It is highly likely that such a drift could not be detected in a few months of monitoring, but it would very likely be detected in 10 years of monitoring. So, again, we have error bars that are non-standard in that they extend to the left in the plot and continue indefinitely to the right.

If we want to express this uncertainty of likelihood of detection in a visual manner, we could employ twodimensional error bars, similar to violin plots, which are often employed to express variable information. Figure C1 shows the likelihood of detecting a particular drift with 2 years of overlap. For drifts considerably smaller than $1.2 \times$ $10^{-4} \mathrm{~W} \mathrm{~m}^{-2} \mathrm{~nm}^{-1} \mathrm{yr}^{-1}$, the likelihood of detection with a 2-year overlap is represented by the width of the green area. Larger drifts can be detected with higher likelihood. Figure $\mathrm{C} 1$ shows the likelihood of a true drift of $1.2 \times$ $10^{-4} \mathrm{~W} \mathrm{~m}^{-2} \mathrm{~nm}^{-1} \mathrm{yr}^{-1}$ being detected in less than 2 years. The height of the blue bar indicates the likelihood, with the linear scale being defined such that the likelihood of detection is $50 \%$ at 2 years; considerably higher likelihood of detection is indicated with more years of overlap. There is also a small (less than 50\%) likelihood that the true drift might be detected in less than 2 years; again, the height of the blue bars indicates the likelihood of detection.

\section{Appendix D: Mathematical structure for optimizing overlap decision choices}

Treating the value of information derived from satellite data as a public good (e.g., weather forecasts and climate services have non-rival and non-excludable characteristics which define public goods in economic theory), total societal benefits are the sum of the benefits realized by all users of the information. Net benefit (NB) is the difference between total benefit (TB) and total cost (TC).

$\mathrm{NB}=\mathrm{TB}\{\operatorname{IVC}[q(o)]\}-\mathrm{TC}[o]$

For purposes of the current discussion we take total costs to simply be a function of the temporal overlap in satellite observations $(o)$. Total costs are an increasing function of $o$ (i.e., the total costs increase as the overlap period increases). On the other hand, total benefits are a more complicated function of the entire process of information creation, communication, use, and decision making (labeled IVC for the information value chain). The benefits of the IVC process are considered to be a function of the quality of the information, $q$, which itself is a function of the temporal overlap in satellite observations $(o)$. The information value chain is a highly nonlinear process and does not necessarily increase as a function of $q(o)$. 
If the objective of "optimizing" satellite observation overlaps is to achieve a specific quality standard, economists would approach this as a cost-effectiveness issue. In this case, the objective is to minimize the costs to achieve the exogenously determined standard. There is no consideration of benefits in this case; $o$ is set to achieve $\bar{q}$, so TB $\{\operatorname{IVC}[\bar{q}(o)]\}$. The outcome is not necessarily societally optimal - the standard could be too strict, in which case net benefits could be negative, or the standard could be too lax, in which case it would be possible to improve societal outcomes by increasing the observational overlap period and increase net benefits. ${ }^{3}$

If instead of a fixed standard $\bar{q}$ the objective is to maximize net societal benefit, then $o$ is chosen to maximize NB. Maximal societal benefits can be identified as a function of the temporal overlap by taking the first derivative of the NB formula with respect to $o .^{4}$

$$
\begin{aligned}
& \partial \mathrm{NB} / \partial o=\partial \operatorname{TB}\{\operatorname{IVC}[q(o)]\} / \partial o-\partial \mathrm{TC} / \partial o \\
& \quad=\frac{\partial \mathrm{TB}}{\partial \operatorname{IVC}} \frac{\partial \operatorname{IVC}}{\partial q} \frac{\partial q}{\partial o}-\partial \mathrm{TC} / \partial o=\mathrm{MB}_{o}-\mathrm{MC}_{o}=0
\end{aligned}
$$

As the terms on the right indicate, the maximum societal benefits are achieved when the marginal benefits $\left(\mathrm{MB}_{o}\right)$ of a change in the overlap period are equal to the marginal costs $\left(\mathrm{MC}_{o}\right)$ of the overlap. ${ }^{5}$ The marginal costs of the overlap period, $\partial \mathrm{TC} / \partial o$, are likely to include additional costs of data collection, assimilation, storage and analysis and may be a fairly linear function of the length of the overlap period. The marginal benefits of increasing the overlap period, however, are represented as a more complex relationship between the overlap period and quality of information $(\partial q / \partial o)$, how changes in information quality manifest through in the information value chain ( $\mathrm{IVC} / \partial q$ ) and how changes in the quality of information provided to decision makers may manifest themselves in potential outcomes ( $\partial \mathrm{TB} / \partial \mathrm{IVC}$ ). While economists have extensive experience and applications in monetizing the value of potential changes in societal outcomes (e.g., lives saved, reduced damages, improved crop yields in agricultures), it is generally much more difficult to (1) identify all of the potential stakeholders and potential outcomes and (2) validly and reliably characterize and quantify the information value chain or how it changes.

\footnotetext{
${ }^{3}$ Rather than taking the standard as a given, the question could be how to set the standard to achieve a societally "optimal" outcome in terms of maximizing societal benefits. This is essentially equivalent to the unconstrained optimization of NB.

${ }^{4}$ For now we do not discuss second-order conditions for maximization. See Morss et al. (2005) for further clarification on secondorder conditions for net benefit maximization which relate specifically to the shapes of the cost and benefit functions.

${ }^{5}$ In economics notation it is common to use the subscript to indicate the relevant factor under discussion - in this case $\mathrm{MB}_{o}$ refers to the marginal benefits of $o$, the observational overlap period.
}

To dependably quantify societal benefits from satellite observations requires understanding the complex relationship between individual instruments, data streams, modeling, communication, decision making, and potential and actual societal outcomes. This requires understanding stakeholders and processes of information creation, transformation, transmission and use in decision making along the entire information value chain through multiple stakeholders with a variety of objectives, resources and constraints. Cooke et al. (2014) develop an illustrative example of such an analysis using the social costs of carbon as a measure of societal benefits and a hypothetical decision framework (i.e., a tipping point that would lead to global climate impact mitigation efforts). 
Author contributions. JH conceived of the idea for this paper and the general techniques to be used; he also provided the data for analysis. EW carried out the calculations, including adapting statistical approaches to the problem, and oversaw the writing. EA worked on the calculations and identified stability requirements for solar and environmental data. LF supplied input on GSICS and complementary methods of verifying stability in satellite records as well as cross verification of results, including those presented in Table 1 . SF and MW provided valuable input on merging of satellite records and applicability of results to developing long-term records. GB offered data and insights into merging of satellite temperature data sets. JL, in consultation with the other co-authors, provided the optimization methodology and economic analysis. TW and PP, as respective principal investigators for the NASA SORCE and the upcoming TSIS missions, advised on the requirements and needs for mission overlap for the solar spectral irradiance climate record. JE supplied input on applicability to climate studies.

Competing interests. The authors declare that they have no conflict of interest.

Acknowledgements. We would like to acknowledge the support of NOAA for support of this research under NWS-13009363. We also acknowledge support from NASA for the production of the data used in this project under CE8NASA contract NAS5-97045. We acknowledge Miami-Dade College for their research support. Mark Weber acknowledges the support of the DFG Research Unit SHARP (Stratospheric Change and its Role for Climate Prediction).

Edited by: William Ward

Reviewed by: two anonymous referees

\section{References}

Adams, C., Bourassa, A. E., Sofieva, V., Froidevaux, L., McLinden, C. A., Hubert, D., Lambert, J.-C., Sioris, C. E., and Degenstein, D. A.: Assessment of Odin-OSIRIS ozone measurements from 2001 to the present using MLS, GOMOS, and ozonesondes, Atmos. Meas. Tech., 7, 49-64, https://doi.org/10.5194/amt-7-492014, 2014.

Araujo-Pradere, E. A., Fuller-Rowell, T. J., and Bilitza, D.: Ionospheric variability for quiet and perturbed conditions, Adv. Space Res., 34, 1914-1921, https://doi.org/10.1016/j.asr.2004.06.007, 2004.

Araujo-Pradere, E. A., Redmon, R., Fedrizzi, M., Viereck, R., and Fuller-Rowell, T. J.: Some characteristics of the ionospheric behavior during solar cycle 23/24 minimum, Sol. Phys., The SunEarth Connection near Solar Minimum, edited by: Bisi, M. M., Emery, B., and Thompson, B. J., https://doi.org/10.1007/s11207011-9728-3, Springer, 2011.

Araujo-Pradere, E. A., Buresova, D., and Fuller-Rowell, T. J.: Initial results of the evaluation of IRI hmF2 performance for minima 22-23 and 23-24, Adv. Space Res., 51, 535-696, https://doi.org/10.1016/j.asr.2012.02.010, 2012.

ASIC3: Achieving Satellite Instrument Calibration for Climate Change (ASIC3), edited by: Ohring, G., avail- able at: http://www.star.nesdis.noaa.gov/star/documents/ ASIC3-071218-webversfinal.pdf (last access: 12 October 2017), 2007.

BenMoussa, A., Gissot, S., Schühle, S., DelZanna, D., and forty additional authors: On-orbit degradation of solar instruments, Sol. Phys., 288, 389-434, https://doi.org/10.1007/s11207-013-0290z, 2013.

Best, F., Adler, A. D. P., Ellington, S. D., Thielman, D. J., and Revercomb, H. E.: On-orbit absolute calibration of temperature with application to the CLARREO mission, Proc. SPIE, 7081, 70810O-1-10, https://doi.org/10.1117/12.795457, 2008.

Bodeker, G. E., Scott, J. C., Kreher, K., and McKenzie, R. L.: Global ozone trends in potential vorticity coordinates using TOMS and GOME intercompared against the Dobson network: 1978-1998, J. Geophys. Res.-Atmos., 106, 23029-23042, 2001.

Bourassa, A. E., Degenstein, D. A., Randel, W. J., Zawodny, J. M., Kyrölä, E., McLinden, C. A., Sioris, C. E., and Roth, C. Z.: Trends in stratospheric ozone derived from merged SAGE II and Odin-OSIRIS satellite observations, Atmos. Chem. Phys., 14, 6983-6994, https://doi.org/10.5194/acp-14-6983-2014, 2014.

Box, G. E. P., Jenkins, G. M., Reinsel, G. C., and Ljung, G. M.: Time series analysis: forecasting and control, 4th Edn., John Wiley \& Sons, 2015.

Brown, S.: Maintaining the long-term calibration of the Jason2/OSTM advanced microwave radiometer through intersatellite calibration, IEEE T. Geosci. Remote, 51, 1531-1543, 2013.

Chander, G., Helder, D. L., Aaron, D., Mishra, N., and Shrestha, A. K.: Assessment of spectral, misregistration and spatial uncertainties inherent in the cross-calibration study, IEEE T. Geosci. Remote, 51, 1282-1296, 2013a.

Chander, G., Hewison, T. J., Fox, N., Wu, X., Xiong, X., and Blackwell, W. J.: Overview of intercalibration of satellite instruments, IEEE T. Geosci. Remote, 51, 1056-1080, 2013b.

Christy, J. R.: Temperature above the surface layer in long-term climate monitoring by the global climate observing system, edited by: Karl, T., Springer, Netherlands, 31, 455-474, 1995.

Christy, J. R., Spencer, R. W., and Lobl, E. S.: Analysis of the merging procedure for the MSU daily temperature time series, J. Climate, 11, 2016-2041, 1998.

Christy, J. R., Spencer, R. W., and Braswell, W. D.: MSU tropospheric temperatures: Dataset construction and radiosonde comparisons, J. Atmos. Ocean. Tech., 17, 1153-1170, 2000.

Cooke, R., Wielicki, B. A., Young, D. F., and Mlynczak, M. G.: Value of information for climate observing systems, Environ. Syst. Decis., 34, 98-109, https://doi.org/10.1007/s10669-0139451-8, 2014.

Donaldson, D. and Storeygard, A.: The view from above: applications of satellite data in economics, J. Econ. Perspect., 30, 171198, https://doi.org/10.1257/jep.30.4.171, 2016.

Ducre'-Robitaille, J.-F., Vincent, L. A., and Boulet, G.: Comparison of techniques for detection of discontinuities in temperature series, Int. J. Climatol., 23, 1087-1101, https://doi.org/10.1002/joc.924, 2003.

Dudok de Wit, T.: A method for filling gaps in solar irradiance and solar proxy data, Astron. Astrophys., 533, https://doi.org/10.1051/0004-6361/201117024, 2011.

Dudok de Wit, T., Kretzschmar, M., Aboudarham, J., Amblard, P.O., Auchère, F., and Lilensten, J.: Which solar EUV indices are 
best for reconstructing the solar EUV irradiance?, Adv. Space Res., 42, 903-911, 2008.

Eckert, E., von Clarmann, T., Kiefer, M., Stiller, G. P., Lossow, S., Glatthor, N., Degenstein, D. A., Froidevaux, L., GodinBeekmann, S., Leblanc, T., McDermid, S., Pastel, M., Steinbrecht, W., Swart, D. P. J., Walker, K. A., and Bernath, P. F.: Drift-corrected trends and periodic variations in MIPAS IMK/IAA ozone measurements, Atmos. Chem. Phys., 14, 25712589, https://doi.org/10.5194/acp-14-2571-2014, 2014.

Feldman, D. R., Algieri, C. A., Ong, J. R., and Collins, W. D.: CLARREO shortwave observing system simulation experiments of the twenty-first century: simulator design and implementation, J. Geophys. Res., 116, https://doi.org/10.1029/2010JD015350, 2011.

Feldman, D. R., Collins, W. D., and Paige, J. L.: Pan-spectral observing system simulation experiments of shortwave reflectance and long-wave radiance for climate model evaluation, Geosci. Model Dev., 8, 1943-1954, https://doi.org/10.5194/gmd-8-19432015, 2015.

Fioletov, V. E., Bodeker, G. E., Miller, A. J., McPeters, R. D., and Stolarski, R.: Global and zonal total ozone variations estimated from ground-based and satellite measurements: 1964-2000, J. Geophys. Res., 107, 4647, https://doi.org/10.1029/2001JD001350, 2002.

Fox, N., Green, P., Brindley, H., Russell, J., Smith, D., Lobb, D., Cutter, M., and Barnes, A.: TRUTHS (Traceable Radiometry Underpinning Terrestrial and Helio Studies): A mission to achieve climate quality data, Proc. ESA Living Planet Symposium 2013, Edinburgh, ESA SP-722, December 2013.

Free, M., Durre, I., Aguilar, E., Seidel, D., Peterson, T. C., Eskridge, R. E., Luers, J. K., Parker, D., Gordon, M., Lanzante, J., Klein, S., Christy, J., Schroeder, S., Soden, B., McMillin, L. M., and Weatherhead, E.: Creating Climate Reference Datasets: CARDS Workshop on adjusting radiosonde temperature data for climate monitoring, B. Am. Meteorol. Soc., 891-899, https://doi.org/10.1175/15200477(2002)083<0891:CCRDCW>2.3.CO;2, 2002.

Frith, S. M., Kramarova, N. A., Stolarski, R. S., McPeters, R. D., Bhartia, P. K., and Labow, G. J.: Recent changes in total column ozone based on the SBUV Version 8.6 merged ozone data set, J. Geophys. Res.-Atmos., 119, 9735-9751, 2014.

Fruit, M., Gusarov, A., and Doyle, D.: Testing and qualification of optical glasses for use in a space radiation environment; the advantages and pitfalls of using a parametric approach, Proc. SPIE Int. Soc. Opt. Eng., 633-641, 2002.

Fröhlich C.: Evidence of a long-term trend in total solar irradiance, Astron. Astrophys., 501, L27-L30, https://doi.org/10.1051/0004-6361/200912318, 2009.

Hamilton, J. D.: Time series analysis, vol. 2, Princeton, Princeton University Press, 1994.

Harder, J. W., Lawrence, G., Fontenla, J., Rottman, G. J., and Woods, T. N.: The Spectral Irradiance Monitor: scientific requirements, instrument design, and operation modes, Sol. Phys., 230, 141-167, 2005a.

Harder J. W., Fontenla, J., Lawrence, G., Woods, T., and Rottman, G.: The Spectral Irradiance Monitor: Measurement (SIMM) equations and calibration, Sol. Phys., 230, 169-204, 2005b.

Harder, J. W., Thuillier, G., Richard, E. C., Brown, S. W., Lykke, K. R., Snow, M., McClintock, W. E., Fontenla, J. M., Woods,
T. N., and Pilewskie, P.: The SORCE SIM Solar Spectrum: comparison with recent observations, Sol. Phys., 263, 3-24, https://doi.org/10.1007s11207-010-9555-y, 2010.

Hewison, T. J., Wu, X., Yu, F., Tahara, Y., Hu, X., Kim, D., and Koenig, M.: GSICS Inter-calibration of infrared channels of geostationary imagers using Metop/IASI, IEEE T. Geosci. Remote, 15, https://doi.org/10.1109/TGRS.2013.2238544, 2013.

Hood, L. L. and Zhou, S.: Stratospheric effects of 27-day solar ultraviolet variations: An analysis of UARS MLS ozone and temperature data, J. Geophys. Res., 103, 3629-3638, https://doi.org/10.1029/97JD02849, 1998.

Hubert, D., Lambert, J.-C., Verhoelst, T., Granville, J., Keppens, A., Baray, J.-L., Bourassa, A. E., Cortesi, U., Degenstein, D. A., Froidevaux, L., Godin-Beekmann, S., Hoppel, K. W., Johnson, B. J., Kyrölä, E., Leblanc, T., Lichtenberg, G., Marchand, M., McElroy, C. T., Murtagh, D., Nakane, H., Portafaix, T., Querel, R., Russell III, J. M., Salvador, J., Smit, H. G. J., Stebel, K., Steinbrecht, W., Strawbridge, K. B., Stübi, R., Swart, D. P. J., Taha, G., Tarasick, D. W., Thompson, A. M., Urban, J., van Gijsel, J. A. E., Van Malderen, R., von der Gathen, P., Walker, K. A., Wolfram, E., and Zawodny, J. M.: Ground-based assessment of the bias and long-term stability of $14 \mathrm{limb}$ and occultation ozone profile data records, Atmos. Meas. Tech., 9, 2497-2534, https://doi.org/10.5194/amt-9-2497-2016, 2016.

Hurrell, J. and Trenberth, K.: Spurious trends in satellite MSU temperatures from merging different satellite records, Nature, 386 , 164-167, https://doi.org/10.1038/386164a0, 1997.

Jaxk, R., Chen, J. L., Wang, X. L., Lund, R., and Lu, Q. Q.: A review and comparison of changepoint detection techniques for climate data, J. Appl. Meteorol. Clim., 46, 900-915, https://doi.org/10.1175/JAM2493.1, 2007.

JCGM - Joint Committee for the Guides in Metrology, JCGM 101: available at: http://www.bipm.org/en/publications/guides/ gum.html (last access: 12 October 2017), 2008.

Karl, T. R. and Williams, C. N.: An approach to adjusting climatological time series for discontinuous inhomogeneities, J. Appl. Meteorol. Clim., 26, 1744-1763, https://doi.org/10.1175/15200450(1987)026<1744:AATACT>2.0.CO;2, 1987.

Karl, T. R., Williams Jr., C. N., Young, P. J., and Wendland, W. M.: A model to estimate the time of observation bias associated with monthly mean maximum, minimum, and mean temperature for the United States, J. Clim. Appl. Meteorol., 25, 145-160, 1986.

Laxminarayan, R. and Macauley, M. K. (Eds.): The value of information: methodological frontiers and new applications in environment and health, Springer Netherlands, $304 \mathrm{pp}$., https://doi.org/10.1007/978-94-007-4839-2, 2012.

Loeb, N. G., Nanalo-Smith, N., Su, W., Shankar, M., and Thomas, S.: CERES top-of-Atmosphere Earth radiation budget climate data record: Accounting for in-orbit changes in instrument calibration, Remote Sens., 8, 1-14, https://doi.org/10.3390/rs8030182, 2016.

Logan, J. A., Staehelin, J., Megretskaia, I. A., Cammas, J. P., Thouret, V., Claude, H., and Fröhlich, M.: Changes in ozone over Europe: Analysis of ozone measurements from sondes, regular aircraft (MOZAIC) and alpine surface sites, J. Geophys. Res.Atmos., 117, https://doi.org/10.1029/2011JD016952, 2012.

Lukashin, C., Wielicki, B. A., Young, D. F., Thome, K., Jin, Z., and Sun, W.: Uncertainty estimates for imager reference inter-calibration with CLARREO reflected solar 
spectrometer, IEEE T. Geosci. Remote, 51, 1425-1436 https://doi.org/10.1109/TGRS.2012.2233480, 2013.

Macauley, M. K.: The value of information: measuring the contribution ofspace-derived earth science data to resource management, Space Policy, 22, 274-282, 2006.

MacDonald, A. E.: A global profiling system for improved weather and climate prediction, B. Am. Meteorol. Soc., 86, 1747, https://doi.org/10.1175/BAMS-86-12-1747, 2005.

Marchenko, S. V. and DeLand, M. T.: Solar spectral irradiance changes during cycle 24, Astrophys. J., 789, 1-17, https://doi.org/10.1088/0004-637X/789/2/117, 2014.

McClintock W. E., Rottman G. J., and Woods T. N.: Solar-Stellar Irradiance Comparison Experiment II (SOLSTICE II): Instrument concept and design, Sol. Phys., 230, 225-258, 2005a.

McClintock W. E., Snow, M., and Woods, T. N.: Solar-Stellar Irradiance Comparison Experiment II (SOLSTICE II): Pre-launch and on-orbit calibrations, Sol. Phys., 230, 259-294, 2005 b.

Mitchell, T. D. and Jones, P. D.: An improved method of constructing a database of monthly climate observations and associated high-resolution grids, Int. J. Climatol., 25, 693-712, https://doi.org/10.1002/joc.1181, 2005.

Morss, R., Miller, K. A., and Vasil, M. S.: A systematic economic approach to evaluating public investment in observations for weather forecasting, Mon. Weather Rev., 133, 374-388, 2005.

National Research Council: Issues in the integration of research and operational satellite Ssystems for climate research: Part I. science and design. Committee on Earth Studies, Space Studies Board, NRC, 2000a.

National Research Council: Reconciling observations of global temperature change, National Academy Press, Washington DC, 2000b.

NISTIR 7047: Satellite Instrument Calibration for Measuring Global Climate Change, edited by: Ohring, G., Wielicki, B., Spencer, R., Emery, W., and Datla, R., available at: http://ws680. nist.gov/publication/get_pdf.cfm?pub_id=104376 (last access: 12 October 2017), 2004.

Ohring, G., Wielicki, B., Spencer, R., Emery, B., and Datla, R.: Satellite instrument calibration for measuring global climate change: report of a workshop, B. Am. Meteorol. Soc., 86, 13031013, https://doi.org/10.1175/BAMS-86-9-1303, 2005.

Pagaran J., Harder, J. W., Webber, M., Floyd, L. E., and Burrows, J. P.: Intercomparison of SCIAMACHY and SIM vis-IR irradiance over several solar rotational timescales, Astron. Astrophys., 528, https://doi.org/10.1051/0004-6361/201015632, 2011.

Penckwitt, A. A., Bodeker, G. E., Stoll, P., Lewis, J., von Clarmann, T., and Jones, A.: Validation of merged MSU4 and AMSU9 temperature climate records with a new 2002-2012 vertically resolved temperature record, Atmos. Meas. Tech. Discuss., https://doi.org/10.5194/amtd-8-235-2015, 2015.

Peterson, T. C., Easterling, D. R., Karl, T. R., Groisman, P., Nicholls, N., Plummer, N., Torok, S., Auer, I., Boehm, R., Gullett, D., Vincent, L., Heino, R., Tuomenvirta, H., Mestre, O., Szentimrey, T., Salinger, J., Forland, E. J., Hanssen Bauer, I., Alexandersson, H., Jones, P., and Parker, D.: Homogeneity adjustments of in situ atmospheric climate data: a review, Int. J. Climatol., 18, 1493-1517, 1998.

Rahpoe, N., Weber, M., Rozanov, A. V., Weigel, K., Bovensmann, H., Burrows, J. P., Laeng, A., Stiller, G., von Clarmann, T., Kyrölä, E., Sofieva, V. F., Tamminen, J., Walker, K., Degenstein,
D., Bourassa, A. E., Hargreaves, R., Bernath, P., Urban, J., and Murtagh, D. P.: Relative drifts and biases between six ozone limb satellite measurements from the last decade, Atmos. Meas. Tech., 8, 4369-4381, https://doi.org/10.5194/amt-8-4369-2015, 2015.

Randel, W. J. and Thompson, A. M.: Interannual variability and trends in tropical ozone derived from SAGE II satellite data and SHADOZ ozonesondes, J. Geophys. Res., 116, D07303, https://doi.org/10.1029/2010JD015195, 2011.

Salby, M. and Callaghan, P.: Sampling error in climate properties derived from satellite measurements: consequences of undersampled diurnal variability, J. Climate, 10, 18-36, 1997.

Santer, B. D., Wigley, T. M. L., Meehl, G. A., Wehner, M. F., Mears, C., Schabel, M., Wentz, F. J., Ammann, C., Arblaster, J., Bettge, T., Washington, W. M., Taylor, K. E., Boyle, J. S., Brüggemann, W., and Doutriaux, C.: Influence of satellite data uncertainties on the detection of externally forced climate change, Science, 300, 1280-1284, https://doi.org/10.1126/science.1082393, 2003.

Schrijver, C. J., Livingston, W. C., Woods, T. N., and Mewaldt, R. A.: The minimal solar activity in 2008-2009 and its implications for long term climate modeling, Geophys. Res. Lett., 38, https://doi.org/10.1029/2011GL046658, 2011.

Slater, P. N., Biggar, S. F., Thome, K. J., Gellman, D. I., and Spyak, P. R.: Vicarious radiometric calibrations of EOS sensors, J. Atmos. Ocean. Tech., 13, 349-359, 1996.

Smith, T. M., Reynolds, R. W., Peterson, T. C., and Lawrimore, J.: Improvements to NOAA's historical merged land-ocean surface temperature analysis (1880-2006), J. Climate, 21, 2283-2296, 2008.

Snow, M., McClintock, W. E., Rottman, G., and Woods, T. N.: Solar-Stellar Irradiance Comparison Experiment II (SOLSTICE II): Examination of the Solar-Stellar Comparison Technique, Sol. Phys., 230, 295-324, 2005.

Staehelin, J., Kerr, J., Evans, R., and Vanicek, K.: Comparison of total ozone measurements of Dobson and Brewer spectrophotometers and recommended transfer functions, Tech. Rep., WMO, World Meteorological Organization Global Atmosphere Watch (WMO-GAW) Report 149, available at: http://library.wmo.int/ pmbged/wmo-td1147.pdf (last access: 12 October 2017), 2003.

Stolarski, R. S. and Frith, S. M.: Search for evidence of trend slowdown in the long-term TOMS/SBUV total ozone data record: the importance of instrument drift uncertainty, Atmos. Chem. Phys., 6, 4057-4065, https://doi.org/10.5194/acp-6-4057-2006, 2006.

Tegtmeier, S., Hegglin, M. I., Anderson, J., Bourassa, A., Brohede, S., Degenstein, D., and Jones, A.: SPARC Data Initiative: A comparison of ozone climatologies from international satellite limb sounders, J. Geophys. Res.-Atmos., 118, https://doi.org/10.1002/2013JD019877, 2013.

Thorne, P. W., Parker, D. E., Christy, J. R., and Mears, C. A.: Uncertainties in climate trends: lessons from upper-air temperature records, B. Am. Meteorol. Soc., 86, 1437-1442, 2005.

Thuillier G., Floyd, L., Woods, T. N., Cebula, R., Hilsenrath, E., Hers, M., and Labs, D.: Solar irradiance reference spectra for two solar active levels, Adv. Space Res., 34, 256-261, 2004.

Tobin, D., Holz, R., Nagle, F., and Revercomb, H.: Characterization of the climate absolute radiance and refractivity observatory (CLARREO) ability to serve as an infrared satellite intercalibration reference, J. Geophys. Res., 121, 4258-4271, https://doi.org/10.1002/2016JD024770, 2016. 
Toohey, M. and von Clarmann, T.: Climatologies from satellite measurements: the impact of orbital sampling on the standard error of the mean, Atmos. Meas. Tech., 6, 937-948, https://doi.org/10.5194/amt-6-937-2013, 2013.

Toohey, M., Hegglin, M. I., Tegtmeier, S., Anderson, J., Añel, J. A., Bourassa, A., and Brohede, S.: Characterizing sampling biases in the trace gas climatologies of the SPARC Data Initiative, J. Geophys. Res.-Atmos., 118, 11847-11862, https://doi.org/10.1002/jgrd.50874, 2013.

Viereck, R. A., Floyd, L. E., Crane, P. C., Woods, T. N., Knapp, B. G., Rottman, G., Weber, M., Puga, L. C., and DeLand, M. T.: A composite Mg II index spanning from 1978 to 2003, Adv. Space Res., 2, S10005, https://doi.org/10.1029/2004SW000084, 2004.

Vincent, L.: A Technique for the identification of inhomogeneities in Canadian temperature series, J. Climate, 11, 1094-1104, https://doi.org/10.1175/15200442(1998)011<1094:ATFTIO>2.0.CO;2, 1998.

Vincent, L. A., Zhang, X., Bonsal, B. R., and Hogg, W. D.: Homogenization of daily temperatures over Canada, J. Climate, 15, 1322-1334, 2002.

Weatherhead, E. C., Tiao, G. C., Reinsel, G. C., Frederick, J. E., DeLuisi, J. J., Choi, D., and Tam, W. K.: Analysis of long-term behavior of ultraviolet radiation measured by Robertson-Berger meters at 14 sites in the United States, J. Geophys. Res.-Atmos., 102, 8737-8754, 1997.

Weatherhead, E. C., Reinsel, G. C., Tiao, G. C., Meng, X. L., Choi, D., Cheang, W. K., Keller, T., DeLuisi, J., Wuebbles, D. J., Kerr, J. B., Miller, A. J., Oltmans, S. J., and Frederick, J. E.: Factors affecting the detection of trends: statistical considerations and applications to environmental data, J. Geophys. Res., 103, 1714917161, https://doi.org/10.1029/98JD00995, 1998.

Weatherhead, E. C., Reinsel, G. C., Tiao, G. C., Jackman, C. H., Bishop, L., Hollandsworth Frith, S. M., DeLuisi, J., Keller, T., Oltmans, S. J., Fleming, E. L., Wuebbles, D. J., Kerr, J. B., Miller, A. J., Herman, J., McPeters, R., Nagatani, R. M., and Frederick, J. E.: Detecting the recovery of total column ozone, J. Geophys. Res.-Atmos., 105, 22201-22210, https://doi.org/10.1029/2000JD900063, 2000.

Weatherhead, E. C., Wielicki, B., and Ramaswamy, V.: Climate observing system simulation experiments. AGU Fall Meeting, San Francisco, California, 14-18 December 2015.

Weber, M., Dikty, S., Burrows, J. P., Garny, H., Dameris, M., Kubin, A., Abalichin, J., and Langematz, U.: The Brewer-Dobson circulation and total ozone from seasonal to decadal time scales, Atmos. Chem. Phys., 11, 11221-11235, https://doi.org/10.5194/acp-11-11221-2011, 2011.

Weber, M., Steinbrecht, W., Roth, C., Coldewey-Egbers, M., Degenstein, D., Fioletov, V. E., Frith, S. M., Froidevaux, L., de Laat, J., Long, C. S., Loyola, D., and Wild, J. D.: Global Climate Stratospheric ozone, in: State of the Climate in 2015, B. Am. Meteorol. Soc., 97, S49-S51, 2016a.
Weber, M., Rahpoe, N., and Burrows, J.: Stability requirements on long-term (satellite) ozone observations and their implications for trend detection, QOS, Edinbrugh, September, $2016 \mathrm{~b}$.

Weber, M., Steinbrecht, W., Frith, S. M., Tweedy, O., ColdeweyEgbers, M., Davis, S., Degenstein, D., Fioletov, Y. E., Froidevaux, L., de Laat, J., Long, C. S., Loyola, D., Roth, C., and Wild, J. D.: Stratospheric ozone, in: State of the Climate in 2016, B. Am. Meteorol. Soc., 98, S49-S51, https://doi.org/10.1175/2017BAMSStateoftheClimate.1, 2017.

Wentz, F. J. and Schabel, M.: Effects of orbital decay on satellitederived lower-tropospheric temperature trends, Nature, 394, 661-664, 1998.

Wielicki, B. A., Young, D. F., Mlynczak, M. G., Thome, K. J., Leroy, S., Corliss, J., and Anderson, J. G.: Achieving climate change absolute accuracy in orbit, B. Am. Meteorol. Soc., 94, 1519-1539, 2013.

Willson, R. C. and Hudson, H. S.: The sun's luminosity over a complete solar cycle, Nature, 351, 42-44, 1991.

Willson, R. C. and Mordvinov, A. V.: Secular total solar irradiance trend during solar cycles 21-23, Geophys. Res. Lett., 30, 1199, https://doi.org/10.1029/2002GL016038, 2003.

WMO: Guide to Climatological Practices WMO-No. 100, ISBN 978-92-63-10100-6. available at: https://public.wmo.int/en/ resources/library/guide-climatological-practices-wmo-100 (last access: 12 October 2017), 2011a.

WMO: Guide to Climatological Practices: Technical specification for the evolution and future hosting of the WMO Database of Observational user requirements and observing system capabilities, 3rd Edn., 2011b.

WMO: TD-No. 341: Calculation of Monthly and Annual 30-years standard normals (prepared by a meeting of experts, Washington, March 1989) [WCDP-No. 10], 1989.

WMO: UNEP, Scientific Assessment of Ozone Depletion, available at: https://www.esrl.noaa.gov/csd/assessments/ozone/2014/ (last access: 12 October 2017.) 2014.

Wu, X., Hewison, T., and Tahara, Y.: GSICS GEO-LEO intercalibration: baseline algorithm and early results, SPIE Proc. Ser., 7456, https://doi.org/10.1117/12.825460, 2009.

Wulfmeyer, V., Hardesty, M., Turner, D., Behrendt, A., Cadeddu, M., Di Girolamo, P., Schlüssel, P., van Baelen, J., and Zus, F.: A review of the remote sensing of lower-tropospheric thermodynamic profiles and its indispensable role for the understanding and the simulation of water and energy cycles, Rev. Geophys., 7456, 745604, https://doi.org/10.1002/2014RG000476, 2015.

Zou, C. Z. and Qian, H.: Stratospheric temperature climate data record from merged SSU and AMSU-A Observations, J. Atmos. Ocean. Tech., 33, 1967-1984, https://doi.org/10.1175/JTECHD-16-0018.1, 2016. 